\title{
Regulation of Apoptosis by Enteroviruses
}

\begin{abstract}
Yalan Lai 1,2,3t, Mingshu Wang ${ }^{1,2,3+}$, Anchun Cheng ${ }^{1,2,3 *}$, Sai Mao ${ }^{1,2,3}$, Xumin Ou ${ }^{1,2,3}$,

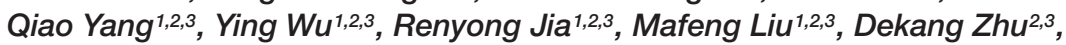
Shun Chen 1,2,3, Shaqiu Zhang 1,2,3, Xin-Xin Zhao 1,2,3, Juan Huang 1,2,3, Qun Gao 1,2,3, Yin Wang ${ }^{2}$, Zhiwen $X u^{2}$, Zhengli Chen ${ }^{2}$, Ling Zhu' ${ }^{2}$, Qihui Luo ${ }^{2}$, Yunya Liu ${ }^{1,2,3}$, Yanling Yu ${ }^{1,2,3}$, Ling Zhang ${ }^{1,2,3}$, Bin Tian ${ }^{1,3}$, Leichang Pan ${ }^{1,3}$, Mujeeb Ur Rehman ${ }^{1,3}$ and Xiaoyue Chen ${ }^{1,2,3}$
\end{abstract}

\begin{abstract}
1 Institute of Preventive Veterinary Medicine, Sichuan Agricultural University, Chengdu, China, ${ }^{2}$ Key Laboratory of Animal Disease and Human Health of Sichuan Province, Sichuan Agricultural University, Chengdu, China, ${ }^{3}$ Avian Disease Research Center, College of Veterinary Medicine, Sichuan Agricultural University, Chengdu, China
\end{abstract}

\section{OPEN ACCESS}

Edited by:

Mohamed Ahmed Ali,

National Research Centre, Egypt

Reviewed by:

Malathi Krishnamurthy,

University of Toledo, United States

Richard Yuqi Zhao,

University of Maryland, Baltimore,

United States

*Correspondence:

Anchun Cheng

chenganchun@vip.163.com

${ }^{\dagger}$ These authors have contributed equally to this work and share first authorship

Specialty section: This article was submitted to Virology,

a section of the journal

Frontiers in Microbiology

Received: 16 January 2020 Accepted: 05 May 2020

Published: 03 June 2020

Citation:

Lai Y, Wang M, Cheng A, Mao S,

Ou X, Yang $Q$, Wu Y, Jia R, Liu M,

Zhu D, Chen S, Zhang S, Zhao X-X, Huang J, Gao Q, Wang Y, Xu Z,

Chen Z, Zhu L, LUo Q, LiU Y, Yu Y,

Zhang L, Tian B, Pan L, Rehman MU and Chen X (2020) Regulation

of Apoptosis by Enteroviruses.

Front. Microbiol. 11:1145.

doi: 10.3389/fmicb.2020.01145
Enterovirus infection can cause a variety of diseases and severely impair the health of humans, animals, poultry, and other organisms. To resist viral infection, host organisms clear infected cells and viruses via apoptosis. However, throughout their long-term competition with host cells, enteroviruses have evolved a series of mechanisms to regulate the balance of apoptosis in order to replicate and proliferate. In the early stage of infection, enteroviruses mainly inhibit apoptosis by regulating the PI3K/ Akt pathway and the autophagy pathway and by impairing cell sensors, thereby delaying viral replication. In the late stage of infection, enteroviruses mainly regulate apoptotic pathways and the host translation process via various viral proteins, ultimately inducing apoptosis. This paper discusses the means by which these two phenomena are balanced in enteroviruses to produce virus-favoring conditions - in a temporal sequence or through competition with each other. This information is important for further elucidation of the relevant mechanisms of acute infection by enteroviruses and other members of the picornavirus family.

Keywords: enterovirus, apoptotic pathway, regulation, balance, viral replication

\section{INTRODUCTION}

Enteroviruses (EVs) are nonencapsulated, single-stranded positive-sense RNA viruses that belong to the genus Enterovirus in the Picornaviridae family. Their complete genomic structure is $\mathrm{VPg}+5^{\prime} \mathrm{UTR}$-[VP0-VP3-VP1/2A(2A1-2A2-2A3)-2B-2C/3A-3B-3C-3D]-3'UTR+Poly(A) (Yang et al., 2017). The main members of the genus Enterovirus are coxsackievirus B3 (CVB3), poliovirus (PV), and EV 71 (EV71). When an EV infects a host animal, it often causes various symptoms (Jubelt and Lipton, 2014). For example, PV can cause neurological symptoms such as aseptic meningitis and poliomyelitis (Korotkova et al., 2016). The symptoms of Coxsackie virus infection range from mild cold symptoms to severe myocarditis, pericarditis, meningitis, and pancreatitis (Muller et al., 2017; Qi and Xiong, 2017). EV71 infection is often characterized by hand, foot and mouth disease (Yee and Laa Poh, 2017). Thus, EV infection can severely endanger human health.

Host cells have developed a number of methods to protect against viral invasion, such as apoptosis. Apoptosis is a process of programmed cell death triggered by various stimuli, including 
viral infection. Since viruses infect host cells by binding to cell surface receptors and then replicate intracellularly, they use most of the host cell transcription and translation systems, and they generate various signals to activate the apoptotic pathway. The removal of infected cells by death receptor- or mitochondriamediated apoptosis is a powerful innate immune mechanism for combating intracellular pathogens, since viral survival depends on cell survival until the pathogen completes its life cycle. The death of infected cells eliminates the environment required for pathogen replication (Harris and Coyne, 2014). When a virus infects cells, the cells initiate an apoptotic process, and viral replication is interrupted as the cells die. Therefore, the death of cells early in viral infection will severely limit production of the virus, thus reducing or eliminating the spread of the progeny virus in the host (Zheng et al., 2017). Because of these host mechanisms, viruses have developed various methods to inhibit apoptosis in order to promote their own replication (Heylbroeck et al., 2000; Yeganeh et al., 2018). On the other hand, the induction of apoptosis can also benefit viruses because apoptosis of virus-infected cells allows the virus to evade host immune recognition. Moreover, in the late stage of viral proliferation, the release of progeny virus can be promoted by triggering of apoptosis, which accelerates infection of nearby living cells (Zhou et al., 2017). Cell death has been reported to be extremely important for viral release (Sun et al., 2016), and the use of apoptosis inhibitors can suppress the release of virus (Deszcz et al., 2004). In summary, the proapoptotic and antiapoptotic effects of a virus on host cells play different roles during the life cycle of the virus. Therefore, the balance between proapoptotic and antiapoptotic processes is critical for viral replication (Harris and Coyne, 2014). With the advancement of research, accumulating evidence has indicated that EVs have evolved a series of mechanisms throughout their long-term competition with host cells that enable them to regulate apoptosis in order to replicate, proliferate and spread.

\section{APOPTOTIC MECHANISM}

In general, two different signaling cascades trigger apoptosis: the extrinsic apoptotic pathway and the intrinsic apoptotic pathway (Liu et al., 2004, 2019; Celine and Miquel, 2012; Guillermo et al., 2014). Caspase protein family members are key molecules in these pathways. Conditions that disrupt intracellular balance, such as mitochondrial dysfunction, calcium imbalance, and DNA mutation, can activate the intrinsic apoptotic pathway, which is mainly composed of and regulated by members of the multidomain B cell lymphoma 2 (Bcl-2) family (Shukla et al., 2017; Jin et al., 2018). This family includes the antiapoptotic molecules Bcl-2 and Bcl-XL (Perciavalle et al., 2012; Wen-Juan et al., 2012; Feng et al., 2018) and the proapoptotic molecules $\mathrm{Bcl}-2$-related X protein (Bax) and BCL-2 antagonist (Bak) (Hsu et al., 1997; Mathai et al., 2005), among others. The intrinsic pathway is activated mainly by the interaction of Bcl-2-like protein 11 (BCL2L11, also known as Bim) or BH3-interacting domain death agonist (Bid) with Bax or Bak. Bax or Bak then undergoes a conformational change (Zhou et al., 2017) and forms heterodimers or homodimers that damage the mitochondrial membrane and reduce the mitochondrial membrane potential. Subsequently, the mitochondria release a protein that binds directly to inhibitor of apoptosis proteins (IAPs), second mitochondria-derived activator of caspases (SMAC), and cytochrome C (Cyt c) in the cytoplasm (Bossy-Wetzel et al., 2014; Kumari et al., 2017), initiating caspase-dependent apoptosis (Xinya et al., 2010). Cyt c binds to procaspase 9 (Shakeri et al., 2017) and the apoptotic protease activator Apaf-1 to form a complex, which cleaves procaspase 9 into caspase 9 and ultimately activates downstream caspase 3 (Liu et al., 2004; Wang G. et al., 2013). In addition, SMAC activates caspase 3 by inhibiting IAPs. Activated caspase-3 cleaves the DNA repair enzyme poly(ADP-ribose) polymerase (PARP), ultimately leading to apoptosis (Penny and Tyler, 2009). In addition, when the intrinsic apoptotic pathway is activated, mitochondria release apoptosis-inducing factor (AIF), a factor that induces caspase-independent apoptosis, in addition to SMAC and Cyt c. AIF is released from mitochondria and translocates to the nucleus, where it activates endogenous endonucleases to cleave nuclear DNA into $50 \mathrm{~kb}$ fragments (Qu et al., 2017).

Initiation of the extrinsic apoptotic pathway begins with the binding of death ligands to their corresponding receptors. Specifically, the death ligands TNF and Fas ligand (FasL) bind to their receptors, TNFR and Fas, and recruit the corresponding death domain (DD) proteins, TNFR-associated DD (TRADD) and FAS-associated DD (FADD) (Liu et al., 2004), respectively. These proteins then bind to procaspase 8 to form the deathinducing signaling complex (DISC) (Jiang et al., 2017), which activates caspase 8 and ultimately activates downstream caspase 3. However, mitochondrial apoptosis and death receptormediated apoptosis are not independent of each other. Activated caspase 8 can cleave Bid to form tBid with proapoptotic activity (Penny and Tyler, 2009), and tBid changes the mitochondrial membrane potential; this process activates the internal apoptotic pathway (Xiao-Min et al., 2004) and thus links the mitochondrial apoptosis with death receptor-mediated apoptosis (Chang et al., 2014; Zamzami et al., 2017).

\section{COUNTERACTION OF APOPTOSIS BY EVs}

To survive and replicate in cells, EVs have developed multiple strategies to block apoptotic processes. As early as 1995, some scholars discovered that PV can block cyclohexylamine-induced apoptosis and described the antiapoptotic functions of RNA viruses for the first time (Tolskaya et al., 1995). With further research, increasing numbers of EVs have been found to inhibit apoptosis.

\section{Cell Sensors and Apoptosis Inhibition}

To protect against virus invasion, host cells can use multiple pattern recognition receptors (PRRs) to detect the presence of pathogens and then activate a series of antiviral responses to 
clear the pathogens. During the EV replication process, doublestranded RNA (dsRNA) is produced as an intermediate, which is recognized by corresponding PRRs, such as retinoic acidinduced gene 1 (RIG-1), melanoma differentiation-related gene 5 (MDA-5) and Toll-like receptor 3 (TLR-3). RIG-1 and MDA5 activation occurs mainly during the later stages of infection and is coordinated with TLR-3 activation (Slater et al., 2010). Studies have shown that host cells can link the recognition of pathogens to the activation of apoptosis, thereby effectively preventing viral replication. RIG-1 mainly recognizes short dsRNA and single-stranded RNA containing $5^{\prime}$-triphosphate ends, while MDA-5 mainly recognizes long dsRNA (Lei et al., 2016). Both can recruit the adaptor protein IFN- $\beta$ promoter stimulator 1 (IPS-1) (also known as Mavs or visa) through their intracellular RNA helicase activity (Kawai et al., 2005) and then recruit nuclear factor $\kappa \mathrm{B}$ inhibitor kinase $\varepsilon$ (IKK $\varepsilon$ ) and TBK1, ultimately causing phosphorylation and dimerization of IRF-3 (Han et al., 2004; Croft et al., 2017). It is worth noting that the IRF-3 homodimer cannot only be transferred to the nucleus and induce the expression of the antiviral protein IFN- $\beta$ but also be transferred to the mitochondrial membrane and form a complex with Bax, ultimately inducing apoptosis. In addition, activated IPS-1 can recruit FADD and receptor interaction serine (Ser)/threonine (Thr) kinase 1 (RIPK1) to form complexes and then recruit and activate pro-caspase 8 to induce apoptosis (Besch et al., 2009; Chattopadhyay and Sen, 2014). TLR-3 primarily recognizes dsRNA in the cytoplasm. When dsRNA binds to TLR-3, it can induce TLR-3 to form a homodimer, thereby exposing the Toll-IL-1 receptor (TIR) domain. TIR domain-containing adaptor-inducing $\beta$-interferon (TRIF) binds to TLR-3-activated IRF-3, TANK-binding kinase1 (TBK-1), and nuclear factor $\kappa \mathrm{B}(\mathrm{NF}-\kappa \mathrm{B})$, which subsequently activates IFN- $\beta$ transcription (de Bouteiller et al., 2005; Sun et al., 2019). Studies have shown that overexpression of TRIF can induce apoptosis and signal transduction along the TRIF-RIPK1FADD-caspase 8 axis (Estornes et al., 2012). In this process, RIPK1 plays an important role; RIPK1 contains a C-terminal RIP isotype interaction motif (RHIM) between its $\mathrm{N}$-terminus and C-terminus that can interact with RHIM at the C-terminus of TRIF through homology (Kaiser and Offermann, 2005). The C-terminus of RIPK1 has a DD that can interact with FADD (Takeuchi and Akira, 2009) so that the apoptosis signal triggered by TLR-3 can be transmitted smoothly (Figure 1).

For EVs, the destruction of cell sensors not only allows the viruses to resist the cellular immune response but also prevents apoptosis from blocking the viral replication process. Numerous studies have shown that cell sensors can be cleaved by a variety of picornaviruses, suggesting the importance of this mechanism for the picornavirus life cycle. For example, cleavage of RIGI has been found in PV-infected cells (Barral et al., 2009), and subsequent studies have revealed that transfection of the $3 \mathrm{C}$ protein alone or addition of the $3 \mathrm{C}$ protein in vitro can lead to RIG-I cleavage, indicating that the $3 \mathrm{C}$ protein can cleave RIG-I (Papon et al., 2009). The 3C protein of EV71 also has a similar effect. It can interact with the caspase recruitment domain at the N-terminus of RIG-I, thereby inhibiting RIG-1 from forming a complex with IPS-1, but it has no inhibitory activity on MDA5
(Lei et al., 2010). The 3C protein of CVB3 can also mediate the cleavage of RIG-I (Feng et al., 2014). Similarly, MDA5 in CVB3-, EV71-, and PV-infected cells undergoes protein degradation in a caspase- and proteasome-independent manner, and the $2 \mathrm{~A}$ protein has been found to be involved in this process (Feng et al., 2014). The above results indicate that cleavage of RIG-I and MDA5 is a common strategy by which EVs resist the interferon response in infected cells. Since RIG-I and MDA5 play important roles in activating IPS- 1 and recruiting FADD, RIPK1, and procaspase 8 and in activating IRF3 and Bax to form a complex, the cleavage of RIG-I and MDA5 by EVs may be related to the regulation of apoptosis.

Studies have shown that many EVs can also cleave IPS-1, which is a key protein in both the interferon response and apoptosis. Cleavage of IPS-1 can inactivate downstream signal transduction. In EV71-infected cells, the EV712A protein cleaves IPS- 1 at the region between the proline-containing region and the transmembrane domain (Wang B. et al., 2013). In addition, the $3 \mathrm{C}$ protein of $\mathrm{CVB} 3$ can cleave IPS-1 in its proline-rich region, causing it to relocate from the mitochondrial membrane and eliminating its downstream signaling (Mukherjee et al., 2011). The 2A protein of CVB3 can also mediate IPS-1 cleavage (Feng et al., 2014). During PV infection, both the $3 \mathrm{C}$ and $2 \mathrm{~A}$ proteins can cleave IPS-1 (Feng et al., 2014). When IPS-1 is cleaved, it can be released from mitochondria, which may cause the death receptor complex to be released from the mitochondrial anchor, thereby inhibiting apoptosis (Wang B. et al., 2013). Notably, EVs often use the same strategy to target specific host factors, but EVs use a variety of mechanisms when cleaving IPS-1.

In addition, phenomenon of TRIF cleavage consistent with that caused by $3 \mathrm{C}$ protein overexpression alone has been observed in CVB3-infected cells, confirming that the 3C protein is the enzyme responsible for cleavage of TRIF; the cleavage sites are located at the N-terminus and C-terminus of TRIF. The C-terminal RHIM motif of TRIF plays an important role in the transduction of apoptotic signals in the TRIF-RIPK1FADD-caspase 8 axis. Therefore, cleavage of TRIF hinders not only the initiation of interferon transcription but also apoptosis (Mukherjee et al., 2011). Similar cleavage of TRIF has been observed in EV71-infected cells (Lei et al., 2011), indicating that this may be a common function of the EV 3C protein. However, whether TRIF can also prevent apoptosis after cleavage by EV71 has not been confirmed and needs further study (Table 1).

\section{PI3K/Akt Pathway and Apoptosis Inhibition}

Regulation of the PI3K/Akt survival pathway is also an important mechanism by which EVs inhibit apoptosis. The PI3K/Akt survival pathway, which is composed mainly of PI3K and Akt, is a key antiapoptotic signaling pathway in vivo. PI3K activates Akt by phosphorylating Thr 308 and Ser 473 on Akt, and activated Akt phosphorylates various substrates to directly or indirectly to help cells survive. On the one hand, activated Akt can directly phosphorylate Ser 136 on Bad, Ser 184 on Bax, and Ser 196 on caspase 9, causing them to lose their ability to promote apoptosis and thereby effectively blocking apoptosis. 


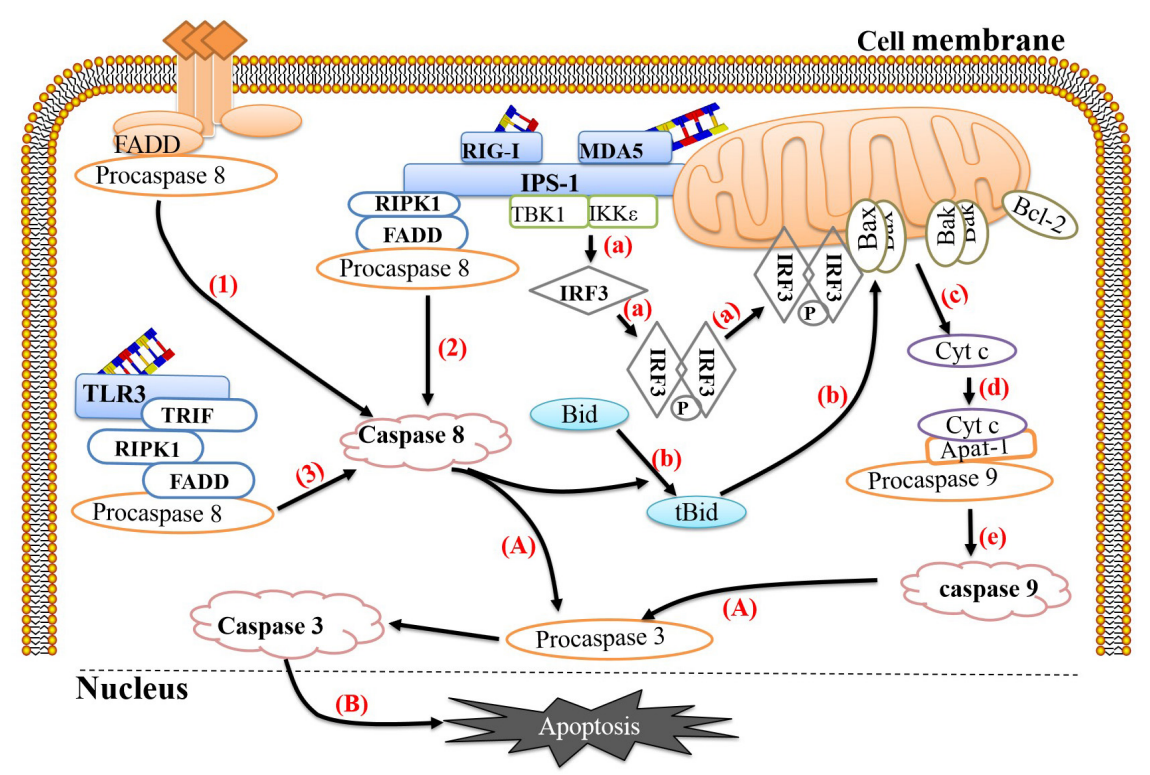

FIGURE 1 | Link between pathogen recognition and apoptosis. (1) The death ligands TNF and FasL bind to their corresponding receptors, TNFR and Fas, and recruit TRADD and FADD, respectively, which then bind to procaspase 8 to form the death-inducing signaling complex (DISC) to activate caspase 8 . (2) RIG-1 or MDA-5 recognizes viral dsRNA and recruits IPS-1. Activated IPS-1 recruits FADD and RIPK1 to form a complex and then recruits and activates procaspase 8 . (3) TLR-3 recognizes viral dsRNA in the cytoplasm and exposes the TIR domain. The adaptor TRIF containing the TIR domain binds to RIPK. The C-terminus of RIPK1 has a death domain (DD), which can interact with FADD, after which FADD recruits and activates procaspase 8. (a) Activated IPS-1 can also recruit IKK $\varepsilon$ and TBK1, causing phosphorylation and dimerization of IRF-3. The IRF-3 homodimer can translocate to the mitochondrial membrane and form a complex with Bax. (b) Activated caspase 8 can cleave Bid to form tBid with proapoptotic activity, which can induce Bax and Bak to insert into the outer mitochondrial membrane. (c) Bax or Bak undergoes conformational changes and forms heterodimers or homodimers, thereby destroying the mitochondrial membrane and reducing the mitochondrial membrane potential. Subsequently, mitochondria release Cyt c into the cytoplasm. (d,e) Cyt c, procaspase 9 and Apaf-1 combine to form a complex that cleaves procaspase 9 into caspase 9. (A) Caspase 9 and caspase 8 cleave procaspase 3 into caspase 3. (B) Caspase 3 translocates to the nucleus and activates proteins, ultimately leading to apoptosis. The image content has been borrowed from other articles in the literature (Croft et al., 2017; Sun et al., 2019).

On the other hand, activated Akt can affect cell survival by altering the activity of transcription factors such as NF- $\kappa$ B. Aktmediated phosphorylation of NF- $\kappa \mathrm{B}$ activates its transcription function, enabling NF- $\kappa \mathrm{B}$ to enhance the expression of the antiapoptotic protein $\mathrm{Bcl}-\mathrm{xl}$ and thereby promote cell survival. In

TABLE 1 | Host proteins cleaved by enterovirus protease(s) during inhibition of apoptosis.

\begin{tabular}{llll}
\hline Host protein & Virus(es) & Protease(s) & References \\
\hline RIG-I & PV & 3C & $\begin{array}{l}\text { Barral et al., 2009; Feng } \\
\text { et al., 2014 } \\
\end{array}$ \\
& EV71 & SC & $\begin{array}{l}\text { Lei et al., 2010; Feng et al., } \\
\text { 2014 }\end{array}$ \\
& CVB3 & 3C & Feng et al., 2014 \\
MDA5 & PV & 2A & Feng et al., 2014 \\
& EV71 & 2A & Feng et al., 2014 \\
IPS-1 & CVB3 & 2A & Feng et al., 2014 \\
& PV & 3C 2A & Wang B. et al., 2013; Feng \\
& & & et al., 2014 \\
& EV71 & 2A & Wang B. et al., 2013 \\
& CVB3 & 3C 2A & Mukherjee et al., 2011 \\
TRIF & EV71 & 3C & Lei et al., 2011 \\
& CVB3 & 3C & Mukherjee et al., 2011
\end{tabular}

addition, mammalian rapamycin (mTOR) is an important target downstream of Akt that can be activated by phosphorylation of Akt. It can control the translation of specific mRNAs, regulate protein synthesis and affect cell proliferation (Kim et al., 2001; Autret et al., 2008; Daxing et al., 2009; Shi et al., 2013; Li et al., 2018; Noorolyai et al., 2019).

In the early stage of EV infection, the mitogen-activated protein kinase (MAPK)/ERK signaling pathway can be activated together with the PI3K/AKT pathway; this phenomenon has been observed in a variety of susceptible cells (Wong et al., 2005; Xie et al., 2016). The MAPK family can regulate a variety of cellular programs, including cell proliferation, the immune response, and apoptosis (Wang et al., 2012). PV interacts with cell receptors to induce phosphorylation of c-Jun amino terminal kinase (JNK) in the MAPK family. Activated JNK can enhance the activity of the transcription factor AP-1, thereby promoting the expression of proapoptotic proteins such as Bax, FasL, and TNF. It can also act on mitochondria through downstream signal transduction and promote Cyt $c$ release. During PV infection of IMR5 cells, activation of JNK can activate Bax-dependent apoptosis, however, it also activates the PI3K/Akt pathway. Activated Akt can phosphorylate apoptotic signal-regulating kinase 1 (ASK1), an upstream regulatory factor of JNK, and thus negatively regulate JNK activation, thereby delaying the activation of the proapoptotic protein Bax and effectively attenuating apoptosis 
and prolonging cell survival (Autret et al., 2008). A similar phenomenon has also been observed in EV71- and CVB3infected cells (Esfandiarei et al., 2004; Zhang et al., 2014b), suggesting that such a process may be widespread in EV-infected cells and may be related to EV-mediated prolongation of cell survival for completion of replication (Figure 2). Unfortunately, the specific details of the mechanisms underlying this process, such as the viral proteins that are involved, have not been thoroughly studied and require further exploration. Notably, EV71 can also simultaneously activate ERK1/2 and JNK1/2 of the MAPK family during infection of human intestinal epithelial cells, thereby downregulating TNF- $\alpha$ and FasL of the TNF family. This effectively inhibits apoptosis, extending the survival time of infected cells. When infected cells are treated with ERK1/2 and JNK1/2 inhibitors, the viral titers of EV71 decrease significantly, indicating that activation of these proteins does indeed enhance viral replication (Wang et al., 2015). However, the role of the PI3K/AKT pathway in this process has not been studied, so whether this pathway is activated and whether its activation is related to apoptosis inhibition remain unclear.

\section{Other Mechanisms of Apoptosis Inhibition}

EVs have also developed other ways to inhibit apoptosis. For example, after infecting cells, PV can increase the levels of the endoplasmic reticulum transmembrane protein Herp by regulating cAMP response element binding protein 3 (CREB3) in host cells. Herp is an important component of the endoplasmic reticulum-associated protein degradation pathway. It can reduce the $\mathrm{Ca}^{2+}$ concentration in the host cell cytoplasm by regulating the proteasome-mediated degradation of the $\mathrm{Ca}^{2+}$ release channels inositol 1,4,5-triphosphate receptor (IP3R) and ryanodine receptor (RyR), thereby inhibiting apoptosis (Delpeyroux et al., 2016). The $3 \mathrm{~A}$ and $2 \mathrm{~B}$ proteins of PV may clear the TNF receptor from the cell membrane after $4 \mathrm{~h}$ of infection by affecting the host cell endoplasmic reticulum-glial protein transport pathway, thus inhibiting TNF-mediated apoptosis early in infection (Neznanov et al., 2001). Under normal circumstances, autophagy is a cellular recycling mechanism and is generally considered a prosurvival response (Harris and Coyne, 2014). In the early stage of CVB3 infection of HeLa cells, apoptosis is inhibited via an increase in autophagosome formation (Xin et al., 2014). Similar inhibition of caspase-3 and apoptosis has been observed in the early stage of CVB3 infection in $\mathrm{H} 9 \mathrm{c} 2$ cells (5-10 $\mathrm{h}$ after infection), and studies have shown that CVB3 enhances autophagy by activating calpain ( $\mathrm{Li}$ et al., 2014; Figure 3).

\section{INDUCTION OF APOPTOSIS BY EVs}

Studies investigating EV-mediated inhibition of host cell apoptosis have also found that apoptosis can be induced during $\mathrm{EV}$ infection, which may aid in the release of the progeny virus and accelerate infection of surrounding living cells (Zhou et al., 2017). Various viral proteins play important roles in such virusinduced apoptosis.

\section{C Protein and Apoptosis}

The 3C protein of picornavirus possesses the characteristic motif and activity of a chromoprotein-like cysteine protease. During the replication process, the only ORF of a viral small RNA is translated into a precursor polyprotein that is cleaved by the self-encoded proteases 2A, 3C, and 3CD into structural and nonstructural proteins with biological functional activity. The $3 \mathrm{C}$ protein has a wide range of restriction sites, so it can lyse certain cytokines in cells to regulate apoptosis. During EV71 infection, the EV71 3C protein can directly interact with caspase- 8 and caspase-9, subsequently activating them and thereby indirectly upregulating caspase-3 activation (Song et al., 2018). The 3C protein of EV71 can also induce the cleavage of the DNA repair enzyme PARP by activating caspase, thereby triggering apoptosis (Li et al., 2002), and the 2A protein of EV71 has a similar effect (Kuo et al., 2002). During PV infection, a similar mechanism induces apoptosis by inducing PARP cleavage; this mechanism also involves both the $2 \mathrm{~A}$ and $3 \mathrm{C}$ proteins. This effect of the PV 3C protein may be related to 3C-mediated cleavage of TATA binding protein that affects the normal progression of the cell life cycle (Clark et al., 1993; Barco et al., 2000; Calandria et al., 2004). However, whether the $3 \mathrm{C}$ protein of EV71 also causes PARP cleavage through this mechanism remains to be confirmed. These findings suggest that different EVs may share this strategy but implement it through slightly different mechanisms. The 3C protein of EV71 can also interact with the telomere-binding protein PinX1, which is subsequently cleaved at the specific site Q50-G51. Decreases in the expression of PinX1 can damage DNA in cells, triggering apoptosis ( $\mathrm{Li}$ et al., 2016). Furthermore, the 3C protein of EV71 can cleave the host protein heterologous ribonucleic acid protein A1 (hnRNP A1), preventing the binding of hnRNP A1 to the internal ribosome entry site (IRES) of Apaf- 1 and thereby promoting the transcription and translation of Apaf-1 (Li et al., 2019). In addition, Chau et al. found that the $3 \mathrm{C}$ and $2 \mathrm{~A}$ proteins of $\mathrm{CVB} 3$ can lyse eukaryotic translation initiation factor 4GI (eIF4GI) in host cells, inhibiting cellular translation and ultimately causing cells to undergo morphological changes, shrinkage and other changes related to apoptosis (Chau et al., 2007). CVB3 also activates caspase8 and caspase- 9 by upregulating Bax expression via the $3 \mathrm{C}$ protein (Chau et al., 2007) and regulates the proapoptotic factors Bim, Bax, caspase- 9 and caspase- 3 in HeLa cells via mTOR, a downstream factor in the PI3K/Akt survival pathway (Xin et al., 2013; Table 2).

\section{A Protein and Apoptosis}

The structure and function of the picornavirus 2A protein vary widely among different species. This protein, as a proteolytic enzyme, plays an important role in virus-induced apoptosis. For example, studies have indicated that the $2 \mathrm{~A}$ proteins of $\mathrm{PV}$ and EV71 can cleave eIF4GI in host cells, thereby inhibiting cap-dependent translation of host cell mRNA and preferentially inducing non-cap-dependent translation of apoptotic proteins (Goldstaub et al., 2000; Sh et al., 2002). However, during CVB3 infection, this mechanism is jointly mediated by the $2 \mathrm{~A}$ and $3 \mathrm{C}$ proteins (Chau et al., 2007). In addition, the $2 \mathrm{~A}$ protein of 


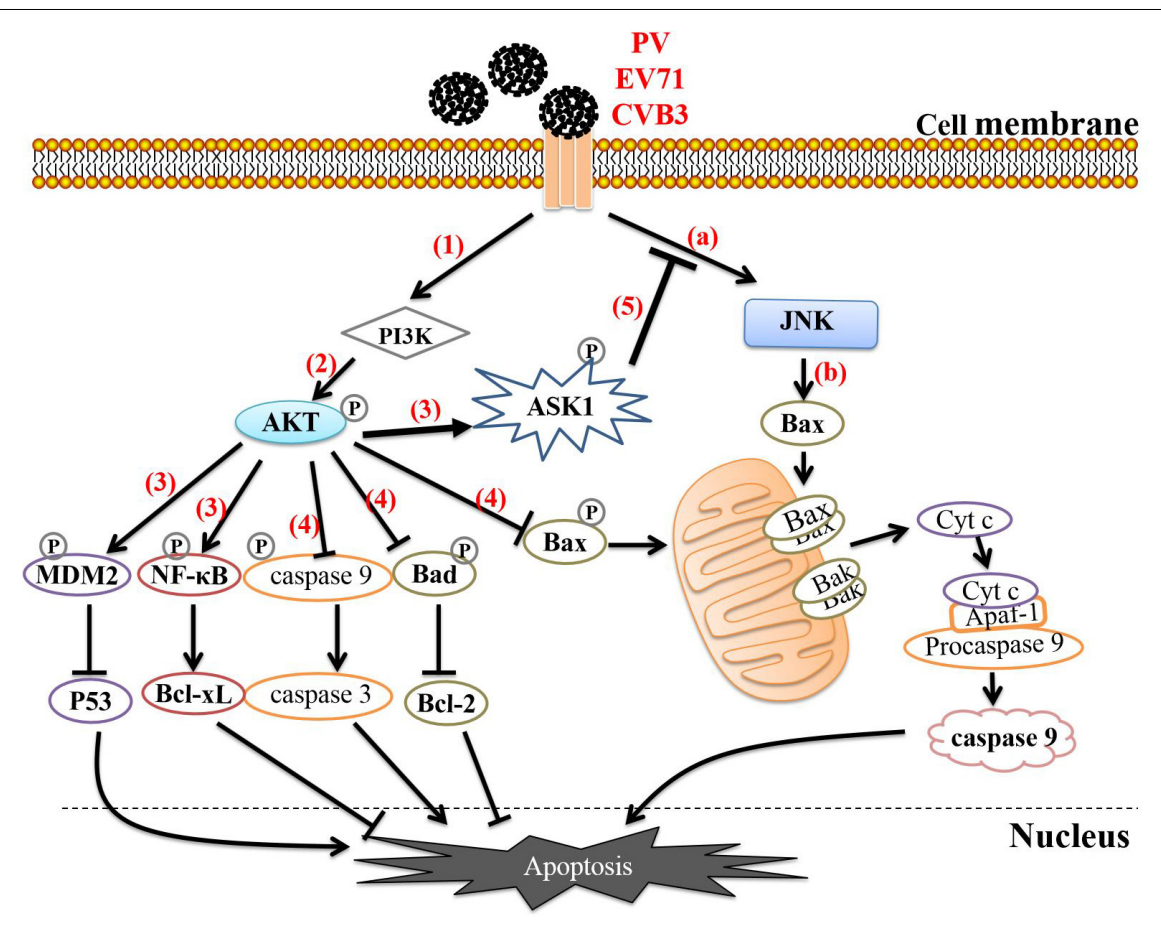

FIGURE 2 | Enteroviruses regulate apoptosis through the PI3K/AKT pathway. (a) Enteroviruses interact with cellular receptors to induce JNK phosphorylation. (b) Activated JNK activates Bax-dependent apoptosis. (1) Enteroviruses interact with cell receptors to activate the PI3K/AKT pathway. (2) PI3K activates Akt by phosphorylating threonine (Thr) 308 and serine (Ser) 473 on Akt. (3) Activated Akt phosphorylates NF-kB, MDM2, and ASK1. Phosphorylation of NF-kB activates its transcription function, allowing it to enhance the expression of the antiapoptotic protein Bcl-xl. Phosphorylated MDM2 can inactivate or degrade P53, thereby blocking the P53-mediated proapoptotic transcription reaction. (4) Activated Akt directly phosphorylates Bad, Bax, and caspase 9, causing them to lose their ability to promote apoptosis and thereby effectively blocking apoptosis. (5) ASK1 is the upstream regulatory factor of JNK, and phosphorylated ASK1 negatively regulates the activation of JNK, thereby delaying activation of the proapoptotic protein Bax and effectively inhibiting apoptosis.

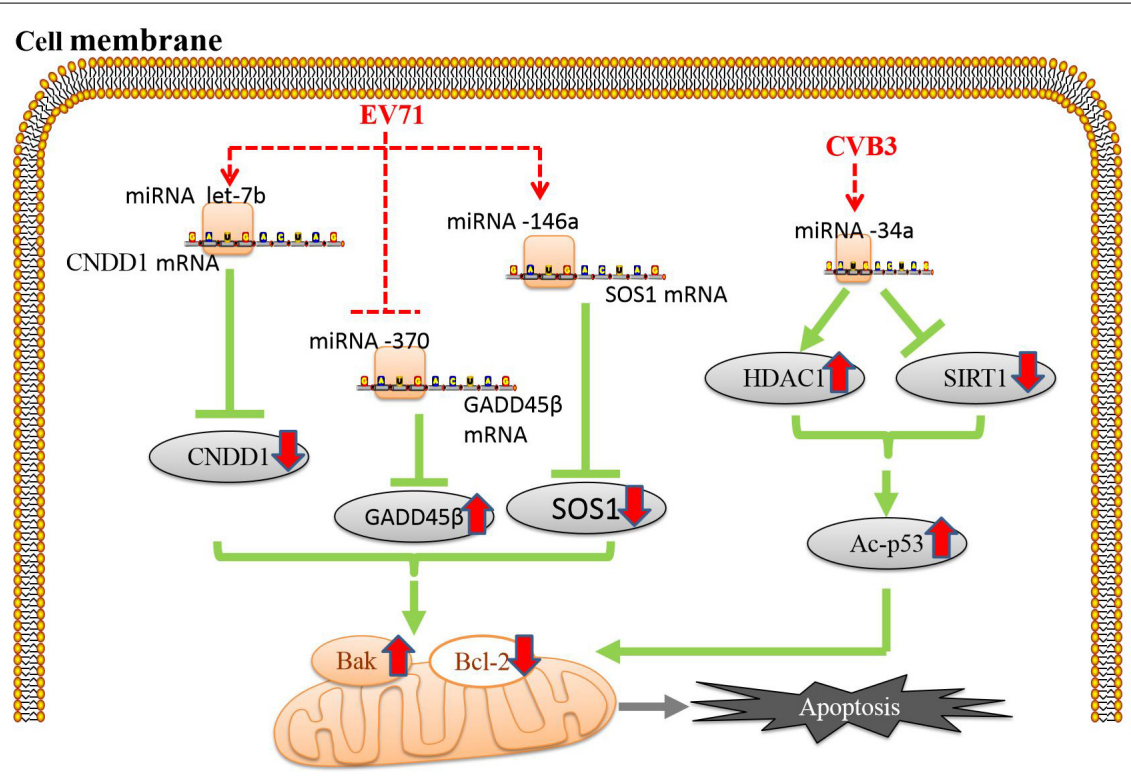

FIGURE 3 | Enteroviruses regulate miRNAs to induce apoptosis. Apoptosis induced by enterovirus infection is associated with the regulation of microRNAs (miRNAs) (Chang et al., 2015; Jiang et al., 2019). The red dotted line indicates the site of enteroviral action, and the red solid arrows indicate the up- or downregulation of the expression of each protein. 
CVB3 cannot only cleave Bid to activate caspase 8 and caspase 9 (Chau et al., 2007) but also cleave death-associated protein 5 (DAP5), a structural homolog of eIF4G. DAP5 can regulate the transcription of apoptotic factors such as Bcl-2, p53, and XIAP driven by IRES elements and is cleaved by the $2 \mathrm{~A}$ protein into N-terminal (DAP5-N) and C-terminal (DAP5-C) fragments. DAP5-N retains the ability to initiate IRES-driven p53 translation but lacks some of the effectiveness of DAP5 in initiating IRESdriven $\mathrm{Bcl}-2$ translation. In addition, DAP5-N increases caspase3 activation and can reduce $\mathrm{Bcl}-2$ expression and enhance p53 translation. Thus, 2A protein signaling leads to increased apoptosis, thereby enhancing viral release (Hanson et al., 2015). Moreover, the 2A protein of EV71 may be a key inducer of apoptosis mediated by the apoptosis-related thioredoxininteracting protein (TXNIP) (Yao et al., 2019; Table 2).

\section{B Protein and Apoptosis}

Viroporin is a type of low-molecular weight virally encoded hydrophobic transmembrane protein with one to three hydrophobic transmembrane domains. These hydrophobic transmembrane regions can interact with the phospholipid bilayer as multimers to form transmembrane channels that change the permeability of the host cell membrane system (Gonzalez and Carrasco, 2003; Nieva et al., 2012). Viroporin thus destroys intracellular ion balance and regulates host cell apoptosis (Bagchi et al., 2010; Crawford et al., 2012). The 2B proteins of EVs such as PV, EV71, and CVB3 all have viroporin properties, indicating the importance of these properties for $2 \mathrm{~B}$ proteins. Specifically, the viroporin property-mediated increases in membrane permeability induced by $2 \mathrm{~B}$ proteins can alter $\mathrm{Ca}^{2+}$ homeostasis to regulate host cell apoptosis. PV increases $\mathrm{Ca}^{2+}$ flux from the endoplasmic reticulum into the cytoplasm by regulating IP3Rs and RyRs on the endoplasmic reticulum. When the $\mathrm{Ca}^{2+}$ concentration in the cytoplasm increases, the $\mathrm{Ca}^{2+}$ concentration in the mitochondria also increases. This regulatory effect causes mitochondrial dysfunction and triggers apoptosis in IMR5 neuroblastoma cells (Brisac et al., 2010; Son et al., 2014). This process may be related to the $2 \mathrm{~B}$ protein of $\mathrm{PV}$ and its viroporin characteristics because increases in $\mathrm{Ca}^{2+}$ concentrations in the cytoplasm can be detected when the $2 \mathrm{~B}$ protein is expressed alone in cells (Aldabe et al., 1997). It has also been found that the $2 \mathrm{~B}$ protein colocalizes with endoplasmic reticulum and Golgi complexes and significantly reduces $\mathrm{Ca}^{2+}$ in the complexes (de Jong et al., 2008). Similarly, CVB3 can induce apoptosis of rat cardiomyocytes by regulating the apoptotic signal transduction process involved in $\mathrm{Ca}^{2+}$ flux (Li et al., 1999), and EV71 can activate calpain by increasing $\mathrm{Ca}^{2+}$ flux after EV71 infection, thereby inducing AIF-mediated caspase-independent apoptosis (Lu et al., 2013). However, the specific mechanisms by which these viruses regulate $\mathrm{Ca}^{2+}$ flux have not been explored. Given the fact that the $2 \mathrm{~B}$ proteins of EVs such as PV, EV71, and CVB3 have viroporin properties, the mechanisms may be related to $2 \mathrm{~B}$ proteins, but this possibility has yet to be confirmed. In addition, EVA71 has been reported to increase Cyt $c$ release and activate caspase- 3 by regulating the recruitment of the proapoptotic protein Bax and inducing a Bax conformational change (Han and Cong, 2017). This phenomenon has been
TABLE 2 | Host proteins cleaved by enterovirus protease(s) during induction of apoptosis.

\begin{tabular}{llll}
\hline Host protein & Virus(es) & Protease(s) & References \\
\hline PinX1 & EV71 & 3C & Li et al., 2016 \\
hnRNP A1 & EV71 & 3C & Li et al., 2019 \\
elF4Gl & PV & 2A & Goldstaub et al., 2000 \\
& EV71 & 2A & Kuo et al., 2002 \\
& CVB3 & 3C 2A & Chau et al., 2007 \\
DAP5 & CVB3 & 2A & Hanson et al., 2015 \\
Bid & CVB3 & 2A & Chau et al., 2007 \\
\hline
\end{tabular}

found to be due to the mitochondrial localization of the EV71 $2 \mathrm{~B}$ protein through its $\mathrm{C}$-terminus and the direct interaction of the $2 \mathrm{~B}$ protein with $\mathrm{Bax}$ at the $\mathrm{N}$-terminus, which triggers redistribution and activation of Bax (Wang and Li, 2019).

EV structural proteins are also involved in inducing apoptosis. The proapoptotic ability of the structural protein VP2 of CVB3 is related to its specific and independent interaction with amino acids $118-136$ of the proapoptotic host cell protein Siva (Henke et al., 2001; Martin et al., 2004). The structural protein VP2 of PV can also bind to Siva and induce apoptosis (Henke et al., 2000).

\section{Other Mechanisms of Apoptosis Induction}

PV can activate JNK by interacting with cellular receptors, thereby inducing Bax conformational change and redistribution from the cytoplasm to mitochondria (Autret et al., 2007). A similar phenomenon has also been observed in EV71- and CVB3-infected cells (Esfandiarei et al., 2004; Zhang et al., 2014b). EV71 also triggers cyclin-dependent protein kinase 5 (Cdk5) by activating the tyrosine kinase $\mathrm{c}-\mathrm{Abl}$, a key factor in neurotoxin signaling in the brain, to ultimately cause neuronal apoptosis (Chen et al., 2010).

Accumulating studies have shown that apoptosis induced by $\mathrm{EV}$ infection is associated with the regulation of microRNAs (miRNAs). miRNAs are a class of small, single-stranded noncoding RNAs widely found in eukaryotes that block the translation of their target mRNAs via posttranscriptional regulation, ultimately inhibiting target gene expression (Tang et al., 2016). In addition to engaging in the abovementioned mechanisms, CVB3 can target miRNA-34a in host cells to downregulate the histone deacetylase SIRT1, consequently increasing Bax expression, inhibiting Bcl-2 expression and inducing apoptosis (Jiang et al., 2019). Furthermore, p53dependent apoptosis can be promoted by upregulation of the expression of the histone deacetylase HDAC1 via miRNA-34a (Zhou et al., 2015). EV71 can increase the expression of cyclin $\mathrm{D}$ (CCND1) by regulating the miRNA let-7b, thereby causing apoptosis of human neuroblastoma cells via cell cycle arrest (Du et al., 2015). EV71 can also regulate the apoptosis-related SOS1 and GADD $45 \beta$ proteins by upregulating miRNA-146a and downregulating miRNA-370, thereby reducing the expression of SOS 1 and increasing the expression of GADD $45 \beta$, respectively, which leads to downregulation of Bcl-2 expression and activation of caspase-3 and PARP (Chang et al., 2015; Figure 3). 


\section{MECHANISMS BY WHICH EVs BALANCE APOPTOSIS}

The above findings indicate that EV infection can both promote and inhibit apoptosis. With continuing research, scholars have gradually proposed a hypothesis to explain this contradictory phenomenon - the existence of a balance between viral promotion and inhibition of apoptosis. On the one hand, EVs can cause apoptosis by blocking the synthesis of host macromolecules to escape the host immune response and promote the release of progeny virus; on the other hand, viral proteins can exhibit antiapoptotic activity, thereby preventing premature death of host cells to prolong the replication time of the virus in living cells (Tolskaya et al., 1995). Timely inhibition and induction of apoptosis are considered two mechanisms that viruses use to achieve optimal replication (Croft et al., 2017).

\section{PI3K/Akt Pathway and Apoptotic Balance}

How can this balance be achieved? According to the literature, different proteins of EVs may simultaneously exhibit antiapoptotic and proapoptotic functions. For example, when expressed in host cells, the $2 \mathrm{~A}$ protein of $\mathrm{PV}$ can cleave eIF4GI and eIF4GII, thereby inhibiting the cap-dependent translation of host cell mRNA. However, the $3 \mathrm{~A}$ protein of PV can neutralize the proapoptotic activity of the $2 \mathrm{~A}$ protein by scavenging TNF receptors on the cell membrane; thus, $\mathrm{PV}$ exhibits antiapoptotic activity in the early stage of infection (the first $4 \mathrm{~h}$ ) (Neznanov et al., 2001). In the later stages of infection, the direct effects of $3 \mathrm{C}, 2 \mathrm{~A}$ and other viral proteins or the cell's defense mechanism activates the caspase protein family through various apoptotic pathways, causing cells to undergo apoptosis. In addition, Mitra et al. (2003), Autret et al. (2008), Zhang et al. (2014b), and other research groups have found that PV and CVB3 proteins can activate the PI3K/Akt survival pathway by interacting with cellular receptors in the early stage of host cell infection and limiting JNK activation or activating the proapoptotic protein Bax. Initial delays in apoptosis allow a virus sufficient time to replicate inside a cell, but subsequent phosphorylation of JNK triggers apoptosis due to massive replication of the virus in the cell, thus allowing complete release of the virus (Autret et al., 2008). The literature reports that EV71 can inhibit apoptosis by activating AKT in the early stage of infection. However, in the late stage of infection, EV71 inhibits AKT phosphorylation by regulating the tumor suppressor gene RASSFs to promote apoptosis (Fengfeng et al., 2015). Therefore, the promotion and inhibition of apoptosis after EV infection may occur sequentially.

However, with increasing research, numerous studies have provided new explanations for the regulation of apoptosis by EVs. Apoptosis inhibition and promotion are not simply sequential; rather, they overlap. The apoptosis rates of infected HeLa cells have been reported to increase linearly within $1.5-2 \mathrm{~h}$ after PV infection, during which time replication of the viral genome is inhibited. However, in the next stage of viral reproduction (after $2 \mathrm{~h}$ of infection), caspase activation and apoptosis are inhibited. After initial entry of PV into a cell, the amount of viral protein produced by the translation of viral RNA, even if small, is sufficient to trigger apoptosis, which is a defense mechanism of the host cell itself. However, the accumulation of viral products with time (after $2 \mathrm{~h}$ of infection) prevents caspase activation (Agol et al., 2000). Notably, PV does not directly inactivate the caspase enzyme but rather prevents its activation, a function that may be related to the need for apoptosis induction in the late stage of infection. The above findings indicate that during $\mathrm{EV}$ infection, both inhibition and promotion of apoptosis may occur simultaneously in the same host cell, analogous to the two scales of Libra, but compete with each other for control over the host cell. This situation allows cells to exhibit either apoptosis or apoptosis inhibition at different stages. The infected cells thus outwardly exhibit sequential inhibition and promotion of apoptosis.

In addition, apoptosis induction during PV infection may be controlled by the balance among survival pathway activation at the early stage of infection, completion of the virus life cycle, and apoptosis at the late stage of infection. Notably, CREB3/Herp may be involved in the delicate balance between proapoptotic signals and antiapoptotic signals during PV infection. Upon infection, PV increases the expression of Herp by regulating CREB3 in host cells. Through this process, Herp expression peaks at $4 \mathrm{~h}$ after infection and then gradually decreases, while the $\mathrm{Ca}^{2+}$ concentration and apoptosis level increase beginning at $4 \mathrm{~h}$ (Delpeyroux et al., 2016). This finding may suggest that apoptotic processes temporally overlap with apoptosis-inhibiting processes. In addition, EV71 infection of HEK 293 cells and RD cells induces upregulation of hsa-miR-494-3p in cells, thereby increasing the expression of the targeted phosphatase gene PTEN. PTEN can activate the PI3K/Akt signaling pathway to inhibit early apoptosis and promote viral replication. Notably, Akt phosphorylation peaks at $0.5 \mathrm{~h}$ after infection and then gradually decreases (Zhao et al., 2018). In addition, during infection of HeLa cells, EV71 can induce the translocation of Src-associated mitotic protein (Sam68) from the nucleus to the cytoplasm. Sam68 can activate the PI3K/Akt signaling pathway by interacting with PI3K p85 to increase viral replication. During this process, Akt phosphorylation gradually increases, peaks at $1 \mathrm{~h}$ after EV71 infection, and then gradually decreases (Zhang et al., 2014a). This phenomenon is somewhat consistent with the findings discussed above.

\section{Autophagy and Apoptotic Balance}

EVs can induce not only apoptosis but also autophagy during the infection process, and both play important roles in the life cycles of EVs. Autophagy is a catabolic pathway that is usually characterized by the formation of bilayer membrane vesicles (autophagosomes) that engulf cytoplasmic organelles and proteins and eventually fuse with lysosomes to reduce their lumen content (Klein and Jackson, 2011). Studies have shown that after EVs infect cells, autophagy and apoptosis can occur simultaneously, and the relationship between the two processes is very complex. For example, when CVB3 infects cells, the direct effects of viral proteins such as $3 \mathrm{C}$ and $2 \mathrm{~A}$ or the cellular defense mechanism activates the caspase protein family through various apoptotic pathways to cause apoptosis, 


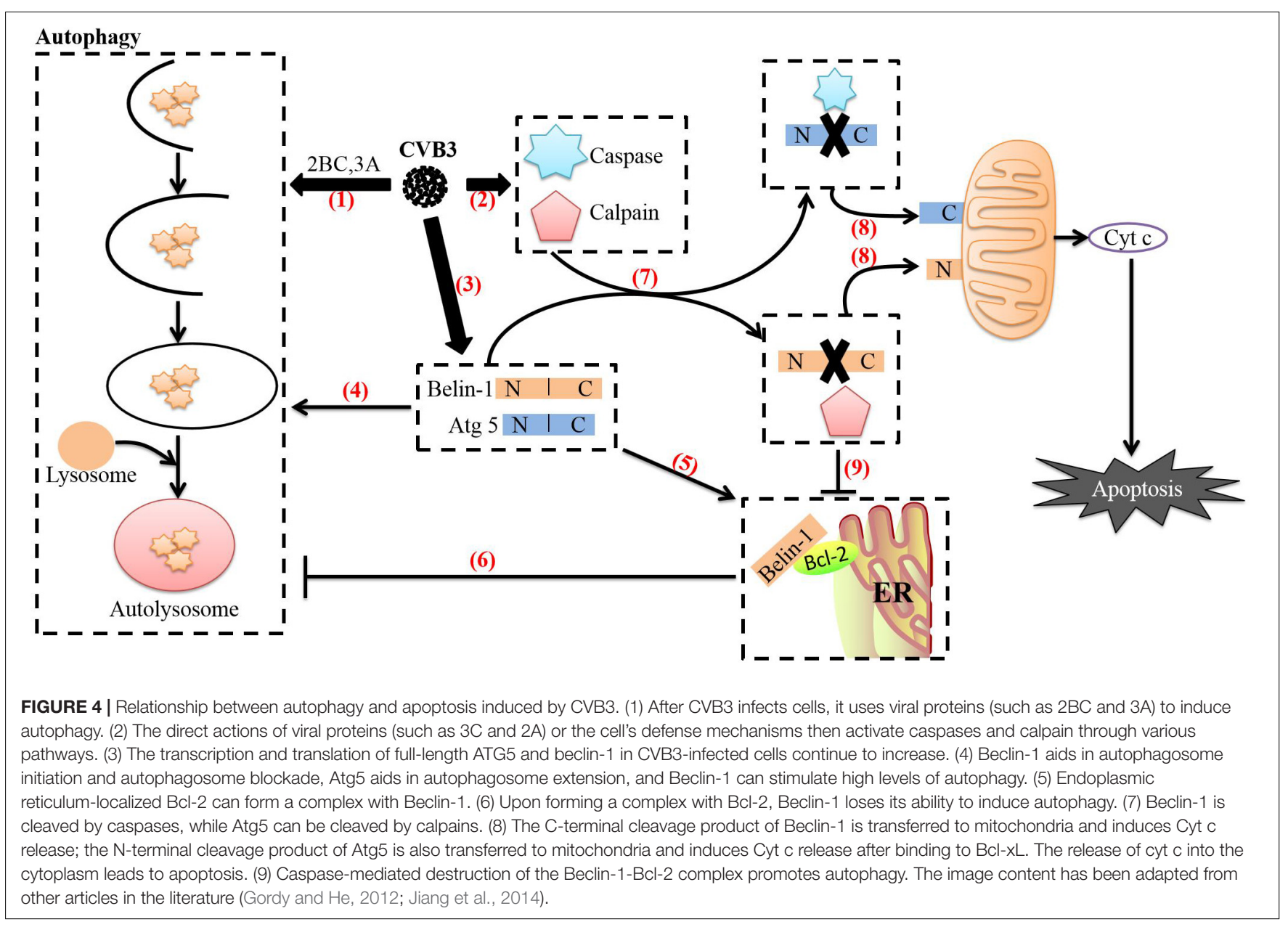

which is conducive to the release and transmission of the progeny virus. However, $\mathrm{CVB} 3$ also requires viral proteins such as $2 \mathrm{BC}$ and $3 \mathrm{~A}$ to support autophagy through the formation of a replication complex that will continually replicate the viral genome to produce progeny virus. Therefore, CVB3 infection induces autophagy to promote replication. While the relationship between apoptosis and autophagy is complex, Shimizuet et al. have demonstrated that autophagy can act as a companion, antagonist or enabler of apoptosis depending on the cell type, stimulation and environment (Shimizu et al., 2004). When autophagy formation is reduced in CVB3-infected cells treated with the autophagy inhibitor 3-methyladenine (3-MA), caspase3 activity is also reduced, and the rate of apoptosis is increased, however, the opposite effects are observed in cells treated with the autophagy inducer rapamycin. In contrast, CVB3 can induce the cleavage of autophagy-related proteins Beclin1 and Atg5, and various caspase inhibitors can prevent the appearance of the Beclin-1 and Atg5 cleavage fragments. These results indicate that $\mathrm{CVB} 3$-induced apoptosis and autophagy are mutually antagonistic. However, it is interesting to note that CVB3-induced apoptosis is not consistent with the peak time of autophagy. The levels of the autophagy marker LC3-II increase from 3 to $9 \mathrm{~h}$ after CVB3 infection and then decrease, while the apoptosis rates of infected cells increase slowly from 3 to $24 \mathrm{~h}$ after infection (Xin et al., 2014). In addition, CVB3 can promote autophagosome formation by activating calpain. Analyses of dynamic curves of calpain and caspase 3 activation have yielded results similar to those described above. Calpain activity continuously increases until $10 \mathrm{~h}$ after CVB3 infection, while caspase- 3 activity is significantly inhibited after infection. However, caspase-3 activity shows a downward trend before beginning to recover and stabilizing $10 \mathrm{~h}$ after infection (Li et al., 2014). This suggests that CVB3-infected cells may undergo a gradual transition from autophagy to apoptosis that may be related to the need for both in the CVB3 life cycle. CVB3 requires the use of autophagosomes during its replication phase. However, apoptosis can clear the virus to a certain extent, because the premature death of infected cells can interrupt viral replication, thus strongly impairing the reproduction of CVB3 (Zhang et al., 2002; Wong et al., 2008). Therefore, CVB3 uses apoptosis mostly to promote the release and spread of progeny virus in the late stage of infection.

CVB3-mediated regulation of the transition between autophagy and apoptosis may be related to several mechanisms. First, as we have discussed previously, CVB3 can promote apoptosis through viral proteins such as $3 \mathrm{C}$ and $2 \mathrm{~A}$ and 

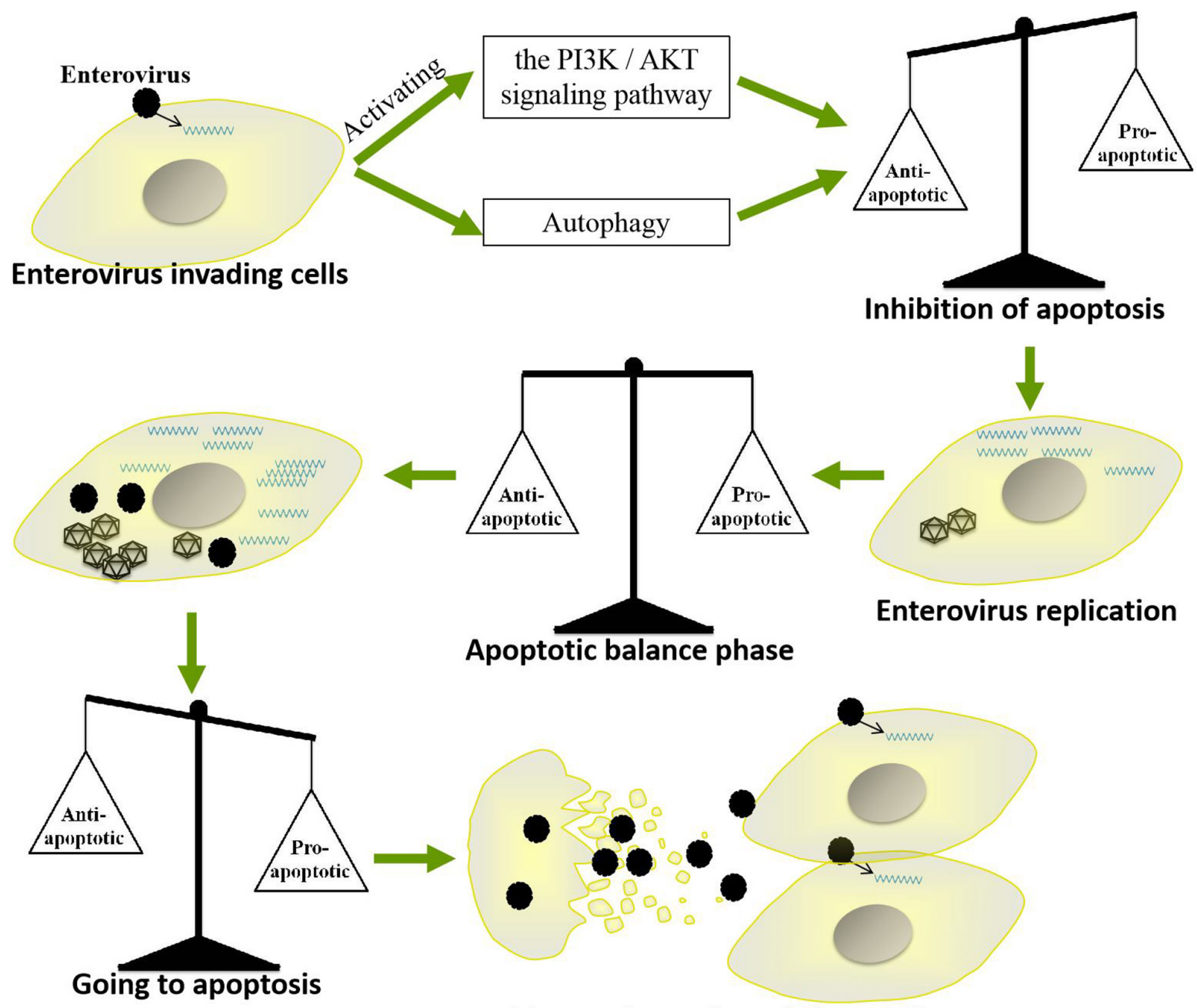

Enterovirus released from cells

FIGURE 5 | Mechanism by which enteroviruses balance apoptosis. Enteroviruses inhibit apoptosis in the early stages of infection to prolong their replication time but induce apoptosis in the late stage of infection to facilitate the release of progeny virus.

ultimately activate caspase 8 (Li et al., 2011), caspase 9 (Rohn et al., 2011) and caspase 3 (Cho et al., 2009; Norman et al., 2010; Wirawan et al., 2010). The autophagy-related protein Beclin-1, which is required for CVB3 to induce autophagy, is a lytic substrate for caspase 8 , caspase 9 , and caspase 3 . The C-terminal cleavage product of Beclin-1 can be transferred to mitochondria and induce Cyt c release (Wirawan et al., 2010). This process may mediate functional crosstalk between autophagy and apoptosis. Second, CVB3 can activate calpain through regulation of $\mathrm{Ca}^{2+}$ flux in cells via the $2 \mathrm{~B}$ protein to increase the formation of autophagosomes. In CVB4-infected cells, calpain 1 and calpain 2 mediate the cleavage of the autophagy-related protein Atg5 (Yoon et al., 2008). The N-terminal cleavage product of Atg5 is then transferred to mitochondria, which induces Cyt $c$ release after binding to Bcl-xL (Yousefi et al., 2006). In addition, caspases can inhibit autophagy by cleaving Atg5 (You et al., 2013). These processes may also be related to crosstalk between autophagy and apoptosis. Finally, interactions between Bcl-2 family proteins regulate not only apoptosis but also autophagy (Luo and Rubinsztein, 2010). CVB3 can regulate the expression of the proapoptotic protein Bax and the antiapoptotic protein $\mathrm{Bcl}-2$ through miRNA-34a and Bax can attenuate Beclin-1-induced autophagy by mediating Beclin-1 cleavage (Luo and Rubinsztein, 2010). Endoplasmic reticulum-localized Bcl-2 can also inhibit Beclin-1-mediated autophagy by forming a complex with Beclin-1 (Pattingre et al., 2005; Maiuri et al., 2007; Strappazzon et al., 2011). Interestingly, caspase-mediated cleavage of Beclin-1 disrupts its interaction with Bcl-2. Although Beclin-1 C-terminal cleavage products and Bcl-2 maintain weak interactions under such conditions, the interaction between $\mathrm{Bcl}-2$ and $\mathrm{N}$-terminal cleavage products completely disappears. Notably, expression of $\mathrm{N}$-terminal cleavage products of Beclin-1 can partially restore the formation of autophagosomes in Beclin-1 shRNA-expressing cells (Zhu et al., 2010), suggesting that caspase-mediated destruction of the Beclin-1-Bcl-2 complex may help promote autophagy. During the transformation from autophagy to 
apoptosis, the transcription and translation of full-length ATG5 and beclin-1 in CVB3-infected cells continues to increase, but overexpression of full-length beclin-1 can inhibit apoptosis and stimulate high-level autophagy (Cho et al., 2009). The balance between cleaved Beclin-1 and full-length Beclin-1 reflects the balance between apoptosis and autophagy (Cho et al., 2009; Wirawan et al., 2010; Zhu et al., 2010). Therefore, this strategy of CVB3 may be used to counteract the cleavage of caspase and calpain, prevent premature cell death, and thus ensure completion of CVB3 replication in autophagosomes (Figure 4).

Increasing numbers of reports have demonstrated that the replication of PV and EV71 is also related to the formation of autophagosomes. The viral proteins $2 \mathrm{BC}$ and $3 \mathrm{~A}$ are necessary for the creation of a double-membrane vesicle environment for viral replication. However, CVB3 can also induce autophagosome accumulation by preventing autophagosome-lysosome fusion, which may be used to prevent the progeny virus from being degraded (Kemball et al., 2010). This phenomenon has not been found during PV and EV71 infection. In addition, although PV has been found to be able to induce both autophagy and apoptosis in separate studies (Barco et al., 2000; Corona Velazquez et al., 2018), there have been no studies on the relationship between the two processes at the same time; thus, further research is needed. It has been reported that EV71 can induce autophagy and apoptosis at the same time and that inhibition of the fusion phase of autophagosomes and lysosomes can promote apoptosis (Xi et al., 2013). In contrast, inhibition of EV71-induced apoptosis can promote the conversion of LC3-I to LC3-II. These mechanisms are similar to the mechanisms by which CVB3 regulates apoptosis and autophagy, suggesting that this strategy for balancing apoptosis in cells may be shared among EVs.

\section{CONCLUSION}

Apoptosis, which mainly eliminates viruses by killing infected cells, is a very important strategy by which cells resist viral

\section{REFERENCES}

Agol, V. I., Belov, G. A., Bienz, K., Egger, D., et al. (2000). Competing death programs in poliovirus-infected cells: commitment switch in the middle of the infectious cycle. J. Virol. 74, 5534-5541. doi: 10.1128/jvi.74.12.5534-5541.2000

Aldabe, R., Irurzun, A., and Carrasco, L. (1997). Poliovirus protein 2BC increases cytosolic free calcium concentrations. J. Virol. 71, 6214-6217. doi: 10.1128/jvi. 71.8.6214-6217.1997

Autret, A., Martin-Latil, S., Brisac, C., Mousson, L., Colbère-Garapin, F., and Blondel, B. (2008). Early phosphatidylinositol 3-kinase/Akt pathway activation limits poliovirus-induced JNK-mediated cell death. J. Virol. 82, 3796-3802. doi: 10.1128/jvi.02020-07

Autret, A., Martin-Latil, S., Mousson, L., Wirotius, A., Petit, F., Arnoult, D., et al. (2007). Poliovirus induces Bax-dependent cell death mediated by c-Jun NH2-terminal kinase. J. Virol. 81, 7504-7516. doi: 10.1128/jvi. 02690-06

Bagchi, P., Dutta, D., Chattopadhyay, S., Mukherjee, A., Halder, U. C., Sarkar, S., et al. (2010). Rotavirus nonstructural protein 1 suppresses virus-induced cellular apoptosis to facilitate viral growth by activating the cell survival pathways during early stages of infection. J. Virol. 84, 6834-6845. doi: 10.1128/ jvi.00225- 10 infection. However, throughout their long-term competition with host cells, EVs have evolved a strategy by which they use apoptosis to promote their own replication and spread. For example, EVs inhibit apoptosis in the early stages of infection to prolong their replication time but induce apoptosis at the late stage of infection to facilitate the release of progeny viruses. Such precise regulation of host cell apoptosis enables EVs to replicate efficiently in cells and successfully spread to neighboring cells. However, the regulatory mechanisms by which these viruses balance the promotion and inhibition of apoptosis are very complicated (Figure 5). Further studies are needed to elucidate the specific mechanisms by which EVs regulate apoptosis and to determine whether as-yet-unidentified pathways are involved. Such studies will also be very important for further clarifying the pathogenic mechanisms of other small RNA viruses and for providing new insights for the development of antiviral drugs.

\section{AUTHOR CONTRIBUTIONS}

YLa and MW contributed to the design of the manuscript. $\mathrm{SM}, \mathrm{XO}, \mathrm{QY}, \mathrm{YWu}, \mathrm{RJ}, \mathrm{ML}, \mathrm{DZ}, \mathrm{SC}$, and QG provided ideas contributing to the conception of this manuscript. BT, SM, and $\mathrm{XO}$ helped to create the figures. AC modified the manuscript. All the authors reviewed the manuscript.

\section{FUNDING}

This work was supported by grants from the National Key Research and Development Program of China (2017YFD0500800), the China Agricultural Research System (CARS-42-17), the Integration and Demonstration of Key Technologies for Goose Industrial Chain in Sichuan Province program (2018NZ0005), and the Sichuan Veterinary Medicine and Drug Innovation Group of the China Agricultural Research System (CARS-SVDIP).

Barco, A., Feduchi, E., and Carrasco, L. (2000). Poliovirus protease 3C pro kills cells by apoptosis. Virology 266, 352-360. doi: 10.1006/viro.1999.0043

Barral, P. M., Sarkar, D., Fisher, P. B., and Racaniello, V. R. (2009). RIG-I is cleaved during picornavirus infection. Virology 391, 171-176. doi: 10.1016/j.virol.2009. 06.045

Besch, R., Poeck, H., Hohenauer, T., Senft, D., Häcker, G., Berking, C., et al. (2009). Proapoptotic signaling induced by RIG-I and MDA-5 results in type I interferon-independent apoptosis in human melanoma cells. J. Clin. Invest. 119, 2399-2411. doi: 10.1172/jci37155

Bossy-Wetzel, E., Newmeyer, D. D., and Green, D. R. (2014). Mitochondrial cytochrome $\mathrm{c}$ release in apoptosis occurs upstream of DEVD-specific caspase activation and independently of mitochondrial transmembrane depolarization. EMBO J. 17, 37-49. doi: 10.1093/emboj/17.1.37

Brisac, C., Téoulé, F., Autret, A., Pelletier, I., and Blondel, B. (2010). Calcium flux between the endoplasmic reticulum and mitochondrion contributes to poliovirus-induced apoptosis. J. Virol. 84:12226. doi: 10.1128/jvi.00994-10

Calandria, C., Irurzun, A., Barco, A., and Carrasco, L. (2004). Individual expression of poliovirus 2Apro and 3Cpro induces activation of caspase- 3 and PARP cleavage in HeLa cells. Virus Res. 104, 39-49. doi: 10.1016/j.virusres.2004.02.042 Celine, P., and Miquel, V. (2012). Mitochondrial biology and Parkinson's disease. Cold Spring Harb. Perspect. Med. 2:a009332. 
Chang, D. W., Xing, Z. V., Peter, M. E., and Yang, X. (2014). Interdimer processing mechanism of procaspase-8 activation. EMBO J. 22, 4132-4142. doi: 10.1093/ emboj/cdg 414

Chang, Y. L., Ho, B. C., Sher, S., Yu, S. L., and Yang, P. C. (2015). miR-146a and miR-370 coordinate enterovirus 71-induced cell apoptosis through targeting SOS1 and GADD45 $\hat{I}^{2}$. Cell Microbiol. 17, 802-818. doi: 10.1111/cmi.12401

Chattopadhyay, S., and Sen, G. C. (2014). dsRNA-activation of TLR3 and RLR signaling: gene induction-dependent and independent effects. J. Interferon Cytokine Res. 34, 427-436. doi: 10.1089/jir.2014.0034

Chau, D. H., Yuan, J., Zhang, H., Cheung, P., Lim, T., Liu, Z., et al. (2007). Coxsackievirus B3 proteases $2 \mathrm{~A}$ and $3 \mathrm{C}$ induce apoptotic cell death through mitochondrial injury and cleavage of eIF4GI but not DAP5/p97/NAT1. Apoptosis 12, 513-524. doi: 10.1007/s10495-006-0013-0

Chen, T. C., Lai, Y. K., Yu, C. K., and Juang, J. L. (2010). Enterovirus 71 triggering of neuronal apoptosis through activation of Abl-Cdk5 signalling. Cell Microbiol. 9, 2676-2688. doi: 10.1111/j.1462-5822.2007.00988.x

Cho, D. H., Jo, Y. K., Hwang, J. J., Lee, Y. M., Roh, S. A., and Kim, J. C. (2009). Caspase-mediated cleavage of ATG6/Beclin-1 links apoptosis to autophagy in HeLa cells. Cancer Lett. 274, 95-100. doi: 10.1016/j.canlet.2008.09.004

Clark, M. E., Lieberman, P. M., Berk, A. J., and Dasgupta, A. (1993). Direct cleavage of human TATA-binding protein by poliovirus protease $3 \mathrm{C}$ in vivo and in vitro. Mol. Cell. Biol. 13, 1232-1237. doi: 10.1128/mcb.13.2.1232

Corona Velazquez, A., Corona, A. K., Klein, K. A., and Jackson, W. T. (2018). Poliovirus induces autophagic signaling independent of the ULK1 complex. Autophagy 14, 1201-1213. doi: 10.1080/15548627.2018.1458805

Crawford, S. E., Hyser, J. M., Utama, B., and Estes, M. K. (2012). Autophagy hijacked through viroporin-activated calcium/calmodulin-dependent kinase kinase- $\beta$ signaling is required for rotavirus replication. Proc. Natl. Acad. Sci. U.S.A. 109, E3405-E3413. doi: 10.1073/pnas.1216539109

Croft, S. N., Walker, E. J., and Ghildyal, R. (2017). Picornaviruses and apoptosis: subversion of cell death. MBio 8:e1009-17. doi: 10.1128/mBio.01009-17

Daxing, X., Crystal, G., Jian, Z., Rey-Chen, P., Haifeng, Z., Luyang, Y., et al. (2009). DAB2IP coordinates both PI3K-Akt and ASK1 pathways for cell survival and apoptosis. Proc. Natl. Acad. Sci. U.S.A. 106, 19878-19883. doi: 10.1073/pnas. 0908458106

de Bouteiller, O., Merck, E., Hasan, U. A., Hubac, S., Benguigui, B., Trinchieri, G., et al. (2005). Recognition of double-stranded RNA by human toll-like receptor 3 and downstream receptor signaling requires multimerization and an acidic pH. J. Biol. Chem. 280, 38133-38145. doi: 10.1074/jbc.M507163200

de Jong, A. S., de Mattia, F., Van Dommelen, M. M., Lanke, K., Melchers, W. J., Willems, P. H., et al. (2008). Functional analysis of picornavirus 2B proteins: effects on calcium homeostasis and intracellular protein trafficking. J. Virol. 82, 3782-3790. doi: 10.1128/jvi.02076-07

Delpeyroux, F., Tangy, F., Pelletier, I., Téoulé, F., and Mirabelli, C. (2016). The CREB3-Herp signaling module limits the cytosolic calcium concentration increase and apoptosis induced by poliovirus. J. Gen. Virol. 97, 2194-2200. doi: 10.1099/jgv.0.000544

Deszcz, L., Seipelt, J., Vassilieva, E., Roetzer, A., and Kuechler, E. (2004). Antiviral activity of caspase inhibitors: effect on picornaviral 2A proteinase. FEBS Lett. 560, 51-55. doi: 10.1016/s0014-5793(04)00069-9

Du, X., Wang, H., Xu, F., Huang, Y., Liu, Z., and Liu, T. (2015). Enterovirus 71 induces apoptosis of SH-SY5Y human neuroblastoma cells through stimulation of endogenous microRNA let-7b expression. Mol. Med. Rep. 12, 953-959. doi: 10.3892/mmr.2015.3482

Esfandiarei, M., Luo, H., Yanagawa, B., Suarez, A., Dabiri, D., Zhang, J., et al. (2004). Protein kinase B/Akt regulates coxsackievirus B3 replication through a mechanism which is not caspase dependent. J. Virol. 78, 4289-4298. doi: 10.1128/jvi.78.8.4289-4298.2004

Estornes, Y., Toscano, F., Virard, F., Jacquemin, G., Pierrot, A., Vanbervliet, B., et al. (2012). dsRNA induces apoptosis through an atypical death complex associating TLR3 to caspase-8. Cell Death. Diff. 19, 1482-1494. doi: 10.1038/ cdd.2012.22

Feng, Q., Langereis, M. A., Lork, M., Nguyen, M., Hato, S. V., Lanke, K., et al. (2014). Enterovirus 2Apro targets MDA5 and MAVS in infected cells. J. Virol. 88, 3369-3378. doi: 10.1128/jvi.02712-13

Feng, S., Zhu, J., Xia, K., Yu, W., Wang, Y., Wang, J., et al. (2018). Cantharidin inhibits anti-apoptotic Bcl-2 family proteins and induces apoptosis in human osteosarcoma cell lines MG-63 and MNNG/HOS via mitochondria-dependent pathway. Med. Sci. Monit. 24, 6742-6749. doi: 10.12659/msm.910294

Fengfeng, Z., Yongjuan, L., Xiong, C., Lanlan, D., Bingfei, Z., Qingqing, C., et al. (2015). RASSF4 promotes EV71 replication to accelerate the inhibition of the phosphorylation of AKT. Biochem. Biophys. Res. Commun. 458, 810-815. doi: 10.1016/j.bbrc.2015.02.035

Goldstaub, D., Gradi, A., Bercovitch, Z., Grosmann, Z., Nophar, Y., Luria, S., et al. (2000). Poliovirus 2A protease induces apoptotic cell death. Mol. Cell. Biol. 20:1271. doi: $10.1128 / \mathrm{mcb} .20 .4 .1271-1277.2000$

Gonzalez, M. E., and Carrasco, L. (2003). Viroporins. FEBS Lett. 552, 28-34. doi: 10.1016/s0014-5793(03)00780-4

Gordy, C., and He, Y. W. (2012). The crosstalk between autophagy and apoptosis: where does this lead? Protein Cell 3, 17-27. doi: 10.1007/s13238-011-1127-x

Guillermo, M. O., Mireia, N. S., Baehrecke, E. H., and Guido, K. (2014). Selfconsumption: the interplay of autophagy and apoptosis. Nat. Rev. Mol. Cell Biol. 15, 81-94. doi: 10.1038/nrm3735

Han, K. J., Su, X., Xu, L. G., Bin, L. H., Zhang, J., and Shu, H. B. (2004). Mechanisms of the TRIF-induced interferon-stimulated response element and NF-kappaB activation and apoptosis pathways. J. Biol. Chem. 279, 15652-15661. doi: 10. 1074/jbc.M311629200

Han, X., and Cong, H. (2017). Enterovirus 71 induces apoptosis by directly modulating the conformational activation of pro-apoptotic protein Bax. J. Gen. Virol. 98, 422-434. doi: 10.1099/jgv.0.000705

Hanson, P. J., Ye, X., Qiu, Y., Zhang, H. M., Hemida, M. G., Wang, F., et al. (2015). Cleavage of DAP5 by coxsackievirus B3 2A protease facilitates viral replication and enhances apoptosis by altering translation of IRES-containing genes. Cell Death Diff. 23:828. doi: 10.1038/cdd.2015.145

Harris, K. G., and Coyne, C. B. (2014). Death waits for no man - Does it wait for a virus? How enteroviruses induce and control cell death. Cytokine Growth. Factor. Rev. 25, 587-596. doi: 10.1016/j.cytogfr.2014.08.002

Henke, A., Launhardt, H., Klement, K., Stelzner, A., Zell, R., and Munder, T. (2000). Apoptosis in coxsackievirus B3-caused diseases: interaction between the capsid protein VP2 and the proapoptotic protein siva. J. Virol. 74, 4284-4290. doi: 10.1128/jvi.74.9.4284-4290.2000

Henke, A., Nestler, M., Strunze, S., Saluz, H. P., Hortschansky, P., Menzel, B., et al. (2001). The apoptotic capability of coxsackievirus B3 is influenced by the efficient interaction between the capsid protein VP2 and the proapoptotic host protein Siva. Virology 289, 15-22. doi: 10.1006/viro.2001. 1082

Heylbroeck, C., Balachandran, S., Servant, M. J., Deluca, C., Barber, G. N., Lin, R., et al. (2000). The IRF-3 transcription factor mediates Sendai virus-induced apoptosis. J. Virol. 74:3781. doi: 10.1128/jvi.74.8.3781-3792.2000

Hsu, Y. T., Wolter, K. G., and Youle, R. J. (1997). Cytosol-to-membrane redistribution of Bax and Bcl-X(L) during apoptosis. Proc. Natl. Acad. Sci. U.S.A. 94, 3668-3672. doi: 10.1073/pnas.94.8.3668

Jiang, D., Li, M., Yu, Y., Shi, H., and Chen, R. (2019). MicroRNA-34a aggravates coxsackievirus B3-induced apoptosis of cardiomyocytes through the SIRT1-p53 pathway. J. Med. Virol. 91, 1643-1651. doi: 10.1002/jmv.25482

Jiang, P., Liu, Y., Ma, H. C., Paul, A. V., and Wimmer, E. (2014). Picornavirus morphogenesis. Microbiol. Mol. Biol. Rev. 78, 418-437. doi: 10.1128/mmbr. 00012-14

Jiang, Y., Yu, M., Hu, X., Han, L., Yang, K., Ba, H., et al. (2017). STAT1 mediates transmembrane TNF-alpha-induced formation of death-inducing signaling complex and apoptotic signaling via TNFR1. Cell Death Diff. 24, 660-671. doi: $10.1038 /$ cdd.2016.162

Jin, L. B., Zhu, J., Liang, C. Z., Tao, L. J., Liu, B., Yu, W., et al. (2018). Paeoniflorin induces G2/M cell cycle arrest and caspase-dependent apoptosis through the upregulation of $\mathrm{Bcl}-2 \mathrm{X}$-associated protein and downregulation of B-cell lymphoma 2 in human osteosarcoma cells. Mol. Med. Rep. 17, 5095-5101. doi: $10.3892 / \mathrm{mmr} .2018 .8464$

Jubelt, B., and Lipton, H. L. (2014). Enterovirus/picornavirus infections. Handb. Clin. Neurol. 123, 379-416. doi: 10.1016/b978-0-444-53488-0. 00018-3

Kaiser, W. J., and Offermann, M. K. (2005). Apoptosis induced by the tolllike receptor adaptor TRIF is dependent on its receptor interacting protein homotypic interaction motif. J. Immunol. 174, 4942-4952. doi: 10.4049/ jimmunol.174.8.4942 
Kawai, T., Takahashi, K., Sato, S., Coban, C., Kumar, H., Kato, H., et al. (2005). IPS1 , an adaptor triggering RIG-I- and Mda5-mediated type I interferon induction. Nat. Immunol. 6, 981-988. doi: 10.1038/ni1243

Kemball, C. C., Alirezaei, M., Flynn, C. T., Wood, M. R., Harkins, S., Kiosses, W. B., et al. (2010). Coxsackievirus infection induces autophagy-like vesicles and megaphagosomes in pancreatic acinar cells in vivo. J. Virol. 84, 12110-12124. doi: $10.1128 /$ jvi.01417-10

Kim, A. H., Khursigara, G., Sun, X., Franke, T. F., and Chao, M. V. (2001). Akt phosphorylates and negatively regulates apoptosis signal-regulating kinase 1 . Mol. Cell. Biol. 21, 893-901. doi: 10.1128/mcb.21.3.893-901.2001

Klein, K. A., and Jackson, W. T. (2011). Picornavirus subversion of the autophagy pathway. Viruses 3, 1549-1561. doi: 10.3390/v3091549

Korotkova, E. A., Gmyl, A. P., Yakovenko, M. L., Ivanova, O. E., Eremeeva, T. P., Kozlovskaya, L. I., et al. (2016). A cluster of paralytic poliomyelitis cases due to transmission of slightly diverged Sabin-2 vaccine virus. J. Virol. 90:5978. doi: 10.1128/jvi.00277-16

Kumari, A., Singh, K. P., Mandal, A., Paswan, R. K., Sinha, P., Das, P., et al. (2017). Intracellular zinc flux causes reactive oxygen species mediated mitochondrial dysfunction leading to cell death in Leishmania donovani. PLoS ONE 12:e0178800. doi: 10.1371/journal.pone.0178800

Kuo, R. L., Kung, S. H., Hsu, Y. Y., and Liu, W. T. (2002). Infection with enterovirus 71 or expression of its 2 A protease induces apoptotic cell death. J. Gen. Virol. 83(Pt 6), 1367-1376. doi: 10.1099/0022-1317-83-6-1367

Lei, X., Liu, X., Ma, Y., Sun, Z., Yang, Y., Jin, Q., et al. (2010). The 3C protein of enterovirus 71 inhibits retinoid acid-inducible gene I-mediated interferon regulatory factor 3 activation and type I interferon responses. J. Virol. 84, 8051-8061. doi: 10.1128/jvi.02491-09

Lei, X., Sun, Z., Liu, X., Jin, Q., He, B., and Wang, J. (2011). Cleavage of the adaptor protein TRIF by enterovirus $713 \mathrm{C}$ inhibits antiviral responses mediated by Toll-like receptor 3. J. Virol. 85, 8811-8818. doi: 10.1128/jvi.00447-11

Lei, X., Xiao, X., and Wang, J. (2016). Innate immunity evasion by enteroviruses: insights into virus-host interaction. Viruses 8:22. doi: 10.3390/v8010022

Li, B., Ding, C. M., Li, Y. X., Peng, J. C., Geng, N., and Qin, W. W. (2018). MicroRNA145 inhibits migration and induces apoptosis in human nonsmall cell lung cancer cells through regulation of the EGFR/PI3K/AKT signaling pathway. Oncol. Rep. 40, 2944-2954. doi: 10.3892/or.2018.6666

Li, B. Y., Qiao, G. F., Zhou, H., Li, W. H., Huang, Z. G., and Zhou, L. W. (1999). Cytosolic-Ca2+ and coxsackievirus B3-induced apoptosis in cultured cardiomyocytes of rats. Zhongguo Yao Li Xue Bao 20, 395-399.

Li, H., Wang, P., Sun, Q., Ding, W. X., Yin, X. M., Sobol, R. W., et al. (2011). Following cytochrome $\mathrm{c}$ release, autophagy is inhibited during chemotherapyinduced apoptosis by caspase 8-mediated cleavage of Beclin 1. Cancer Res. 71, 3625-3634. doi: 10.1158/0008-5472.Can-10-4475

Li, J., Yao, Y., Chen, Y., Xu, X., Lin, Y., Yang, Z., et al. (2016). Enterovirus 71 3C promotes apoptosis through cleavage of PinX1, a telomere binding protein. J. Virol. 91, JVI.02016-JVI.02016.

Li, M., Wang, X., Yu, Y., Yu, Y., Xie, Y., Zou, Y., et al. (2014). Coxsackievirus B3induced calpain activation facilitates the progeny virus replication via a likely mechanism related with both autophagy enhancement and apoptosis inhibition in the early phase of infection: an in vitro study in H9c2 cells. Virus Res. 179, 177-186. doi: 10.1016/j.virusres.2013.10.014

Li, M. L., Hsu, T. A., Chen, T. C., Chang, S. C., Lee, J. C., Chen, C. C., et al. (2002). The $3 \mathrm{C}$ protease activity of enterovirus 71 induces human neural cell apoptosis. Virology 293, 386-395. doi: 10.1006/viro.2001.1310

Li, M. L., Lin, J. Y., Chen, B. S., Weng, K. F., Shih, S. R., Calderon, J. D., et al. (2019). EV71 3C protease induces apoptosis by cleavage of hnRNP Al to promote apaf-1 translation. PLOS ONE 14:e0221048. doi: 10.1371/journal.pone.022 1048

Liu, J., Wei, T., and Kwang, J. (2004). Avian encephalomyelitis virus nonstructural protein $2 \mathrm{C}$ induces apoptosis by activating cytochrome c/caspase-9 pathway. Virology 318, 169-182. doi: 10.1016/j.virol.2003.09.012

Liu, T., Li, X., Wu, M., Qin, L., Chen, H., and Qian, P. (2019). Seneca valley virus 2C and $3 \mathrm{C}$ (pro) induce apoptosis via mitochondrion-mediated intrinsic pathway. Front. Microbiol. 10:1202. doi: 10.3389/fmicb.2019.01202

Lu, J. R., Lu, W.-W., Lai, J.-Z., Tsai, F.-L., Wu, S.-H., Lin, C.-W., et al. (2013). Calcium flux and calpain-mediated activation of the apoptosis-inducing factor contribute to enterovirus 71-induced apoptosis. J. Gen. Virol. 94(Pt 7), 14771485. doi: 10.1099/vir.0.047753-0
Luo, S., and Rubinsztein, D. C. (2010). Apoptosis blocks Beclin 1-dependent autophagosome synthesis: an effect rescued by Bcl-xL. Cell Death. Diff. 17, 268-277. doi: $10.1038 /$ cdd.2009.121

Maiuri, M. C., Le Toumelin, G., Criollo, A., Rain, J. C., Gautier, F., Juin, P., et al. (2007). Functional and physical interaction between Bcl-X(L) and a BH3-like domain in Beclin-1. EMBO J. 26, 2527-2539. doi: 10.1038/sj.emboj.7601689

Martin, U., Nestler, M. T., Zell, R., Sigusch, H. H., and Henke, A. (2004). Characterization of coxsackievirus B3-caused apoptosis under in vitro conditions. Med. Microbiol. Immunol. 193, 133-139. doi: 10.1007/s00430-0030197-7

Mathai, J. P., Marc, G., and Shore, G. C. (2005). BH3-only BIK regulates BAX,BAK-dependent release of $\mathrm{Ca} 2+$ from endoplasmic reticulum stores and mitochondrial apoptosis during stress-induced cell death. J. Biol. Chem. 280, 23829-23836. doi: 10.1074/jbc.m500800200

Mitra, E., Honglin, L., Bobby, Y., Agripina, S., Darya, D., Jianchang, Z., et al. (2003). Protein kinase B/Akt regulates coxsackievirus B3 replication through a mechanism which is not caspase dependent. J. Virol. 78, 4289-4298.

Mukherjee, A., Morosky, S. A., Delorme-Axford, E., Dybdahl-Sissoko, N., Oberste, M. S., Wang, T., et al. (2011). The coxsackievirus B 3C protease cleaves MAVS and TRIF to attenuate host type I interferon and apoptotic signaling. PLoS Pathog. 7:e1001311. doi: 10.1371/journal.ppat.1001311

Muller, I., Vogl, T., Pappritz, K., Miteva, K., Savvatis, K., Rohde, D., et al. (2017). Pathogenic role of the damage-associated molecular patterns S100A8 and S100A9 in coxsackievirus B3-induced myocarditis. Circ. Heart Fail 10, e004125. doi: $10.1161 /$ circheartfailure.117.004125

Neznanov, N., Kondratova, A., Chumakov, K., Angres, B., Zhumabayeva, B., Agol, V., et al. (2001). Poliovirus protein $3 \mathrm{~A}$ inhibits tumor necrosis factor (TNF)induced apoptosis by eliminating the TNF receptor from the cell surface. J. Virol. 75, 10409-10420. doi: 10.1128/jvi.75.21.10409-10420.2001

Nieva, J. L., Madan, V., and Carrasco, L. (2012). Viroporins: structure and biological functions. Nat. Rev. Microbiol. 10, 563-574. doi: 10.1038/ nrmicro2820

Noorolyai, S., Shajari, N., Baghbani, E., Sadreddini, S., and Baradaran, B. (2019). The relation between PI3K/AKT signalling pathway and cancer. Gene 698, 120-128. doi: 10.1016/j.gene.2019.02.076

Norman, J. M., Cohen, G. M., and Bampton, E. T. (2010). The in vitro cleavage of the hAtg proteins by cell death proteases. Autophagy 6, 1042-1056. doi: 10.4161/auto.6.8.13337

Papon, L., Oteiza, A., Imaizumi, T., Kato, H., Brocchi, E., Lawson, T. G., et al. (2009). The viral RNA recognition sensor RIG-I is degraded during encephalomyocarditis virus (EMCV) infection. Virology 393, 311-318. doi: 10. 1016/j.virol.2009.08.009

Pattingre, S., Tassa, A., Qu, X., Garuti, R., Liang, X. H., Mizushima, N., et al. (2005). Bcl-2 antiapoptotic proteins inhibit Beclin 1-dependent autophagy. Cell 122, 927-939. doi: 10.1016/j.cell.2005.07.002

Penny, C., and Tyler, K. L. (2009). Apoptosis in animal models of virus-induced disease. Nat. Rev. Microbiol. 7:144. doi: 10.1038/nrmicro2071

Perciavalle, R. M., Stewart, D. P., Brian, K., John, L., Sandra, M., Madhavi, B., et al. (2012). Anti-apoptotic MCL-1 localizes to the mitochondrial matrix and couples mitochondrial fusion to respiration. Nat. Cell Biol. 14, 575-583. doi: $10.1038 / \mathrm{ncb} 2488$

Qi, X., and Xiong, S. (2017). Intein-mediated backbone cyclization of VP1 protein enhanced protection of CVB3-induced viral myocarditis. Sci. Rep. 7:41485. doi: 10.1038/srep41485

Qu, X., Ding, X., Duan, M., Yang, J., Lin, R., Zhou, Z., et al. (2017). Influenza virus infection induces translocation of apoptosis-inducing factor (AIF) in A549 cells: role of AIF in apoptosis and viral propagation. Arch. Virol. 162, 1-7.

Rohn, T. T., Wirawan, E., Brown, R. J., Harris, J. R., Masliah, E., and Vandenabeele, P. (2011). Depletion of Beclin-1 due to proteolytic cleavage by caspases in the Alzheimer's disease brain. Neurobiol. Dis. 43, 68-78. doi: 10.1016/j.nbd.2010.11. 003

Sh, K. R. K., Hsu, Y. Y., and Liu, W. T. (2002). Infection with enterovirus 71 or expression of its 2A protease induces apoptotic cell death. J. Gen. Virol. 83, $1367-1376$.

Shakeri, R., Kheirollahi, A., and Davoodi, J. (2017). Apaf-1: regulation and function in cell death. Biochimie 135, 111-125. doi: 10.1016/j.biochi.2017.02.001

Shi, W., Hou, X., Li, X., Peng, H., Shi, M., Jiang, Q., et al. (2013). Differential gene expressions of the MAPK signaling pathway in enterovirus 71-infected 
rhabdomyosarcoma cells. Braz. J. Infect. Dis. Off. Publ. Braz. Soc. Infect. Dis. 17, 410-417. doi: 10.1016/j.bjid.2012.11.009

Shimizu, S., Kanaseki, T., Mizushima, N., Mizuta, T., Arakawa-Kobayashi, S., Thompson, C. B., et al. (2004). Role of Bcl-2 family proteins in a non-apoptotic programmed cell death dependent on autophagy genes. Nat. Cell Biol. 6, 1221-1228. doi: 10.1038/ncb1192

Shukla, S., Saxena, S., Singh, B. K., and Kakkar, P. (2017). BH3-only protein BIM: an emerging target in chemotherapy. Eur. J. Cell Biol. 96, 728-738. doi: 10.1016/ j.ejcb.2017.09.002

Slater, L., Bartlett, N. W., Haas, J. J., Zhu, J., Message, S. D., Walton, R. P., et al. (2010). Co-ordinated role of TLR3, RIG-I and MDA5 in the innate response to rhinovirus in bronchial epithelium. PLoS Pathog. 6:e1001178. doi: 10.1371/ journal.ppat.1001178

Son, S. M., Byun, J., Roh, S. E., Kim, S. J., and Mook-Jung, I. (2014). Reduced IRE1 $\alpha$ mediates apoptotic cell death by disrupting calcium homeostasis via the InsP3 receptor. Cell Death Dis. 5:e1188. doi: 10.1038/cddis.20 14.129

Song, F., Xiaoyan, Y., Ting, Z., Zengyan, W., Xiangling, M., Zhaolong, L., et al. (2018). Caspase-3 inhibition attenuates the cytopathic effects of EV71 infection. Front. Microbiol. 9:817. doi: 10.3389/fmicb.2018. 00817

Strappazzon, F., Vietri-Rudan, M., Campello, S., Nazio, F., Florenzano, F., Fimia, G. M., et al. (2011). Mitochondrial BCL-2 inhibits AMBRA1-induced autophagy. EMBO J. 30, 1195-1208. doi: 10.1038/emboj.2011.49

Sun, D., Chen, S., Cheng, A., and Wang, M. (2016). Roles of the picornaviral 3C proteinase in the viral life cycle and host cells. Viruses 8:82. doi: 10.3390/ v8030082

Sun, D., Wen, X., Wang, M., Mao, S., Cheng, A., Yang, X., et al. (2019). Apoptosis and autophagy in picornavirus infection. Front. Microbiol. 10:2032. doi: 10. 3389/fmicb.2019.02032

Takeuchi, O., and Akira, S. (2009). Innate immunity to virus infection. Immunol. Rev. 227, 75-86. doi: 10.1111/j.1600-065X.2008.00737.x

Tang, W. F., Huang, R. T., Chien, K. Y., Huang, J. Y., Lau, K. S., Jheng, J. R., et al. (2016). Host MicroRNA miR-197 plays a negative regulatory role in the enterovirus 71 infectious cycle by targeting the RAN protein. J. Virol. 90, 1424-1438. doi: 10.1128/jvi.02143-15

Tolskaya, E. A., Romanova, L. I., Kolesnikova, M. S., Ivannikova, T. A., Smirnova, E. A., Raikhlin, N. T., et al. (1995). Apoptosis-inducing and apoptosispreventing functions of poliovirus. J. Virol. 69, 1181-1189. doi: 10.1128/jvi.69. 2.1181-1189.1995

Wang, B., Xi, X., Lei, X., Zhang, X., Cui, S., Wang, J., et al. (2013). Enterovirus 71 protease 2Apro targets MAVS to inhibit anti-viral type I interferon responses. PLoS Pathog. 9:e1003231. doi: 10.1371/journal.ppat.1003231

Wang, B., Zhang, H., Zhu, M., Luo, Z., and Peng, Y. (2012). MEK1-ERKs signal cascade is required for the replication of Enterovirus 71 (EV71). Antiviral Res. 93, 110-117. doi: 10.1016/j.antiviral.2011.11.001

Wang, C., Gao, L., Jin, Y., Cardona, C. J., and Xing, Z. (2015). Regulation of host responses and viral replication by the mitogen-activated protein kinases in intestinal epithelial cells infected with Enterovirus 71. Virus Res. 197, 75-84. doi: 10.1016/j.virusres.2014.12.016

Wang, G., Wang, X., Yu, H., Wei, S., Williams, N., Holmes, D. L., et al. (2013). Small-molecule activation of the TRAIL receptor DR5 in human cancer cells. Nat. Chem. Biol. 9, 84-89. doi: 10.1038/nchembio.1153

Wang, H., and Li, Y. (2019). Recent progress on functional genomics research of enterovirus 71. Virol. Sin. 34, 9-21. doi: 10.1007/s12250-018-0071-9

Wen-Juan, G., Zhu, J., and Ai-Ying, W. (2012). [Expression of Bcl-w protein in human small intestinal adenocarcinoma and effect of Bcl-w siRNA on apoptosis in intestinal adenocarcinoma HuTu-80 cells]. Zhonghua zhong liu za zhi [Chin. J. Oncol.] 34:182.

Wirawan, E., Vande Walle, L., Kersse, K., Cornelis, S., Claerhout, S., Vanoverberghe, I., et al. (2010). Caspase-mediated cleavage of Beclin-1 inactivates Beclin-1-induced autophagy and enhances apoptosis by promoting the release of proapoptotic factors from mitochondria. Cell Death Dis. 1:e18. doi: $10.1038 /$ cddis.2009.16

Wong, J., Zhang, J., Si, X., Gao, G., Mao, I., McManus, B. M., et al. (2008). Autophagosome supports coxsackievirus B3 replication in host cells. J. Virol. 82, 9143-9153. doi: 10.1128/jvi.00641-08
Wong, W. R., Chen, Y. Y., Yang, S. M., Chen, Y. L., and Horng, J. T. (2005). Phosphorylation of PI3K/Akt and MAPK/ERK in an early entry step of enterovirus 71. Life Sci. 78, 82-90. doi: 10.1016/j.lfs.2005.04.076

Xi, X., Zhang, X., Wang, B., Wang, T., Wang, J., Huang, H., et al. (2013). The interplays between autophagy and apoptosis induced by enterovirus 71. PLoS ONE 8:e56966. doi: 10.1371/journal.pone.0056966

Xiao-Min, G., Jungyuen, C., Franzin, C. M., Dayong, Z., Reed, J. C., and Marassi, F. M. (2004). Conformation of membrane-associated proapoptotic tBid. J. Biol. Chem. 279, 28954-28960. doi: 10.1074/jbc.m403490200

Xie, G. C., Guo, N. J., Grénman, R., Wang, H., Wang, Y., Vuorenmma, M., et al. (2016). Susceptibility of human tonsillar epithelial cells to enterovirus 71 with normal cytokine response. Virology 494, 108-118. doi: 10.1016/j.virol.2016.04. 016

Xin, L., Juan, Z., Zhiheng, C., Li, Y., Xiaowei, X., Xing, M., et al. (2013). Both PI3Kand mTOR-signaling pathways take part in CVB3-induced apoptosis of Hela cells. DNA Cell Biol. 32, 359-370. doi: 10.1089/dna.2013.2003

Xin, L., Xiao, Z., Ma, X., He, F., Yao, H., and Liu, Z. (2014). Coxsackievirus B3 induces crosstalk between autophagy and apoptosis to benefit its release after replicating in autophagosomes through a mechanism involving caspase cleavage of autophagy-related proteins. Infect. Genet. Evol. 26, 95-102. doi: 10.1016/j.meegid.2014.05.005

Xinya, L., Aleksandar, M., Yang, L., Yeunkyung, S., Qiang, L., and Yan, Z. (2010). The PI3K/Akt pathway inhibits influenza A virus-induced Bax-mediated apoptosis by negatively regulating the JNK pathway via ASK1. J. Gen. Virol. 91, 1439-1449. doi: 10.1099/vir.0.018465-0

Yang, X., Cheng, A., Wang, M., Jia, R., Sun, K., Pan, K., et al. (2017). Structures and corresponding functions of five types of picornaviral $2 \mathrm{~A}$ proteins. Front. Microbiol. 8:1373. doi: 10.3389/fmicb.2017.01373

Yao, C., Hu, K., Xi, C., Li, N., and Wei, Y. (2019). Transcriptomic analysis of cells in response to EV71 infection and 2A pro as a trigger for apoptosis via TXNIP gene. Genes Genomics 41, 343-357. doi: 10.1007/s13258-018-0760-7

Yee, P. T. I., and Laa Poh, C. (2017). Impact of genetic changes, pathogenicity and antigenicity on Enterovirus- A71 vaccine development. Virology 506, 121-129. doi: 10.1016/j.virol.2017.03.017

Yeganeh, B., Ghavami, S., Rahim, M. N., Klonisch, T., Halayko, A. J., and Coombs, K. M. (2018). Autophagy activation is required for influenza A virus-induced apoptosis and replication. Biochim. Biophys. Acta Mol. Cell. Res. 1865, 364-378. doi: 10.1016/j.bbamcr.2017.10.014

Yoon, S. Y., Ha, Y. E., Choi, J. E., Ahn, J., Lee, H., Kweon, H. S., et al. (2008). Coxsackievirus B4 uses autophagy for replication after calpain activation in rat primary neurons. J. Virol. 82, 11976-11978. doi: 10.1128/jvi.010 28-08

You, M., Savaraj, N., Kuo, M. T., Wangpaichitr, M., Varona-Santos, J., Wu, C., et al. (2013). TRAIL induces autophagic protein cleavage through caspase activation in melanoma cell lines under arginine deprivation. Mol. Cell. Biochem. 374, 181-190. doi: 10.1007/s11010-012-1518-1

Yousefi, S., Perozzo, R., Schmid, I., Ziemiecki, A., Schaffner, T., Scapozza, L., et al. (2006). Calpain-mediated cleavage of Atg5 switches autophagy to apoptosis. Nat. Cell Biol. 8, 1124-1132. doi: 10.1038/ncb1482

Zamzami, N., Hamel, C. E. L., Maisse, C., Brenner, C., Muñoz-Pinedo, C., et al. (2017). Bid acts on the permeability transition pore complex to induce apoptosis. Oncogene 19, 6342-6350. doi: 10.1038/sj.onc.1204030

Zhang, H., Cong, H., Song, L., and Tien, P. (2014a). The nuclear protein Sam68 is redistributed to the cytoplasm and is involved in PI3K/Akt activation during EV71 infection. Virus Res. 180, 1-11. doi: 10.1016/j.virusres.2013. 11.020

Zhang, H., Li, F., Pan, Z., Wu, Z., Wang, Y., and Cui, Y. (2014b). Activation of PI3K/Akt pathway limits JNK-mediated apoptosis during EV71 infection. Virus Res. 192, 74-84. doi: 10.1016/j.virusres.2014.07.026

Zhang, H. M., Yanagawa, B., Cheung, P., Luo, H., Yuan, J., Chau, D., et al. (2002). Nip21 gene expression reduces coxsackievirus B3 replication by promoting apoptotic cell death via a mitochondria-dependent pathway. Circ. Res. 90, 1251-1258. doi: 10.1161/01.res.0000024690.69379.5c

Zhao, Q., Xiong, Y., Xu, J., Chen, S., Li, P., Huang, Y., et al. (2018). Host MicroRNA hsa-miR-494-3p Promotes EV71 Replication by Directly Targeting PTEN. Front. Cell Infect. Microbiol. 8:278. doi: 10.3389/fcimb.2018. 00278 
Zheng, C., Zheng, Z., Sun, J., Zhang, Y., Wei, C., Ke, X., et al. (2017). MiR-16-5p mediates a positive feedback loop in EV71-induced apoptosis and suppresses virus replication. Sci. Rep. 7:16422. doi: 10.1038/s41598-017-16616-7

Zhou, L., He, X., Gao, B., and Xiong, S. (2015). Inhibition of histone deacetylase activity aggravates coxsackievirus b3-induced myocarditis by promoting viral replication and myocardial apoptosis. J. Virol. 89, 10512-10523. doi: 10.1128/ jvi.01028-15

Zhou, X., Wenbo, J., Zhongshun, L., Shuai, L., and Xiaozhen, L. (2017). Virus infection and death receptor-mediated apoptosis. Viruses 9:316. doi: 10.3390/ v9110316

Zhu, Y., Zhao, L., Liu, L., Gao, P., Tian, W., Wang, X., et al. (2010). Beclin 1 cleavage by caspase- 3 inactivates autophagy and promotes apoptosis. Protein Cell 1, 468-477. doi: 10.1007/s13238-010-0048-4
Conflict of Interest: The authors declare that the research was conducted in the absence of any commercial or financial relationships that could be construed as a potential conflict of interest.

Copyright (c) 2020 Lai, Wang, Cheng, Mao, Ou, Yang, Wu, Jia, Liu, Zhu, Chen, Zhang, Zhao, Huang, Gao, Wang, Xu, Chen, Zhu, Luo, Liu, Yu, Zhang, Tian, Pan, Rehman and Chen. This is an open-access article distributed under the terms of the Creative Commons Attribution License (CC BY). The use, distribution or reproduction in other forums is permitted, provided the original author(s) and the copyright owner(s) are credited and that the original publication in this journal is cited, in accordance with accepted academic practice. No use, distribution or reproduction is permitted which does not comply with these terms. 